\title{
Molecular mechanisms of stress-induced prefrontal cortical impairment: Implications for mental illness
}

\author{
Avis B. Hains ${ }^{1}$ and Amy F.T. Arnsten ${ }^{1,2}$ \\ ${ }^{1}$ Department of Neurobiology, Yale University School of Medicine, New Haven, Connecticut 06511, USA
}

\begin{abstract}
The symptoms of mental illness often involve weakened regulation of thought, emotion, and behavior by the prefrontal cortex. Exposure to stress exacerbates symptoms of mental illness and causes marked prefrontal cortical dysfunction. Studies in animals have revealed the intracellular signaling pathways activated by stress exposure that induce profound prefrontal cortical impairment: Excessive dopamine stimulation of D1 receptors impairs prefrontal function via cAMP intracellular signaling, leading to disconnection of prefrontal networks, while excessive norepinephrine stimulation of $\alpha 1$ receptors impairs prefrontal function via phosphatidylinositol-protein kinase C intracellular signaling. Genetic studies indicate that the genes disrupted in serious mental illness (bipolar disorder and schizophrenia) often encode for the intracellular proteins that serve as brakes on the intracellular stress pathways. For example, disrupted in schizophrenia 1 (DISCl) normally regulates cAMP levels, while regulator of G protein signaling 4 (RGS4) and diacylglycerol kinase (DGKH) - the molecule most associated with bipolar disordernormally serve to inhibit phosphatidylinositol-protein kinase $C$ intracellular signaling. Patients with mutations resulting in loss of adequate function of these genes likely have weaker endogenous regulation of these stress pathways. This may account for the vulnerability to stress and the severe loss of PFC regulation of behavior, thought, and affect in these illnesses. This review highlights the signaling pathways onto which genetic vulnerability and stress converge to impair PFC function and induce debilitating symptoms such as thought disorder, disinhibition, and impaired working memory.
\end{abstract}

Disturbances in prefrontal cortex (PFC) are evident in numerous neuropsychiatric illnesses including bipolar disorder (e.g., Blumberg et al. 1999, 2002; Glahn et al. 2006), schizophrenia (e.g., Goldman-Rakic 1994; Lewis 1995), and Post-Traumatic Stress Disorder (PTSD) (e.g., Bremner et al. 1995; Southwick et al. 1997; Shin et al. 2006). Functional and morphological weaknesses in PFC have been linked to cognitive deficits that underlie many of the most debilitating symptoms of these disorders. The pathophysiology of mental illnesses is often attributed to the interaction of biological and genomic factors with environmental factors, and the environmental factor most commonly linked to such illnesses is stress (for review, see Mazure 1995). Although the intersections of stress and mental illness have been appreciated for years, the precise mechanisms for stress-induced psychiatric decompensation have eluded researchers.

The diathesis-stress model of mental illness suggests that variables increasing an individual's experience of stress can reveal or exacerbate symptoms of mental illness. Both environmental and biological factors can contribute to stress reactivity. Retrospective and prospective studies of patients with schizophrenia indicate that increases in environmental liability brought upon by "life stressors" such as going away to college, or the death of a loved one, tend to precede the development of symptoms (Brown and Birley 1968; Birley and Brown 1970; Ventura et al. 1989; Fowles 1992). Similarly, in patients with bipolar disorder, stress precipitates episodes and precedes lapses into mania from the euthymic (normal) state (Hammen and Gitlin 1997). Stress is inherent to PTSD, which is caused by exposure to a traumatic event that is experienced as horrific or lifethreatening. For example, recent studies of Hurricane Katrina survivors indicate that hurricane-related stressors play a significant role in the increased incidence of PTSD, suicide, and mood

${ }^{2}$ Corresponding author.

E-mail amy.arnsten@yale.edu; fax (203) 785-5263.

Article is online at http://www.learnmem.org/cgi/doi/10.1101/lm.921708. and anxiety disorders across the socioeconomic spectrum (Kessler et al. 2006, 2008; Galea et al. 2007).

Findings from studies of the effects of stress on the PFC provide valuable knowledge about the role of stress-related neurobiological pathways in psychopathology. In the last two decades, work from our laboratory and others has helped to characterize the consequences of stress on the behavioral, cellular, and molecular operations of the PFC. Animal studies indicate that stress results in similar biochemical, cognitive, and morphological changes to the PFC as those observed in mental illness, for example, loss of dendritic spine density (Radley et al. 2006), PFC cognitive deficits, and dysregulation of intracellular signaling cascades (Birnbaum et al. 2004; Runyan et al. 2005; Dash et al. 2007). Mechanisms of stress-induced PFC changes are beginning to provide valuable insight regarding PFC deficits in mental illness. For example, it is now clear that PTSD involves dysregulation of norepinephrine (NE), a neuromodulator central to PFC function and the stress response, and emerging knowledge from genetic studies indicates that genes disrupted in bipolar disorder and schizophrenia encode proteins that otherwise regulate the stress response and permit optimal PFC functioning. Thus, biological and genetic factors contribute to dysregulated stress reactivity among individuals vulnerable to mental illness. This review highlights the pathways and molecules onto which genetic or neurobiological vulnerability and stress converge to impair PFC function and induce debilitating symptoms such as thought disorder, disinhibition of behavior and affect, and impaired working memory.

\section{PFC dysfunction in mental illness}

The PFC is critical to regulating and executing thought, emotion, and action utilizing appropriate judgment, flexibility, and attention (e.g., Arnsten and Robbins 2002). The PFC is also needed to inhibit interference from distracting stimuli and to suppress inappropriate memories, actions, and feelings. The organization of 
appropriate reactions to a changing environment requires representation of information not currently in the environment, i.e., representational knowledge. The ability to represent information is often referred to as working memory or the "mental sketchpad," and these operations allow for the maintenance and manipulation of information and control over new, incoming information processing (e.g., Goldman-Rakic 1995b). These processes ultimately regulate impulses, language, attention, decision-making, and error correction and are commonly referred to as the executive functions (e.g., Botvinick et al. 2001; Miller and Cohen 2001; Corbetta and Shulman 2002).

Given the central role of working memory and representational knowledge in the executive operations of the PFC, the majority of animal studies described below assess behavioral and physiological performance on working memory tasks. Many of the studies examining PFC functions in rats utilized the spatial delayed alternation task ( $\mathrm{T}$ maze), a task that requires spatial working memory, but also behavioral inhibition (inhibiting the tendency to return to a rewarded location) and regulation of distractibility (the rats are picked up and returned to the start box on each trial). Thus, these data address a range of PFC cognitive operations. Electrophysiological and iontophoresis studies have been limited to recordings from dorsolateral PFC (dlPFC) in monkeys performing a spatial working memory task (described below). These findings may apply to other PFC regions and cognitive operations, especially those functions requiring complex network interactions and inhibition of prepotent responses. However, these findings may not apply to all PFC abilities, and one must be cautious in generalizing this information to other PFC functions.

Single unit recording studies in non-human primates have helped to reveal the circuitry underlying working memory: The dIPFC maintains modality-specific information via recurrent excitatory connections among local networks of pyramidal neurons (Goldman-Rakic 1990, 1995a,b). These networks, or microcircuits, remain active through a delay period, thereby holding information "online." The strength of these network connections is dynamically modulated by NE acting at $\alpha 2 \mathrm{a}-$ adrenoceptors ( $\alpha 2 \mathrm{a}$-ARs) (Wang et al. 2007). Conversely, selective inhibition by $\gamma$-aminobutyric acid (GABA) interneurons and dopamine (DA) receptor signaling (Vijayraghavan et al. 2007) sculpts, or tunes, microcircuits to respond selectively, for example, to fire following cues presented in a particular portion of the visuospatial field, but not following other spatial locations (Fig. 1; for review, see Goldman-Rakic 1995b). The ability to represent information in a properly tuned manner depends on the network having the appropriate connections for the current cognitive demand. Thus, any disruption in the balance of excitation and inhibition, or inappropriate neuromodulation, can profoundly impact network actions and result in suboptimal PFC function. It is important to note that the structural and functional integrity of these working memory microcircuits is relevant to a variety of cognitive operations. For example, PFC neurons can fire in relationship to abstract rules, can maintain information in the presence of distracting stimuli, and can serve as the basis for behavioral inhibition, for example, having to look away from a visual stimulus, or having to reverse reward contingencies (e.g., Chao and Knight 1998; Knight et al. 1999; Wallace and Miller 2003; Aron et al. 2004; Muhammad et al. 2006).

The primate PFC can be divided into several subregions with specialized, but related, operations (for reviews, see Davidson and Irwin 1999; Aron et al. 2004; Pessoa 2008). The dorsal and lateral PFC project to sensory cortices, premotor cortices, striatum, and the cerebellum for the regulation of attention and action (Selemon and Goldman-Rakic 1985, 1988; Cavada and GoldmanRakic 1989; Middleton and Strick 2000; Romanski 2004; Barbas et

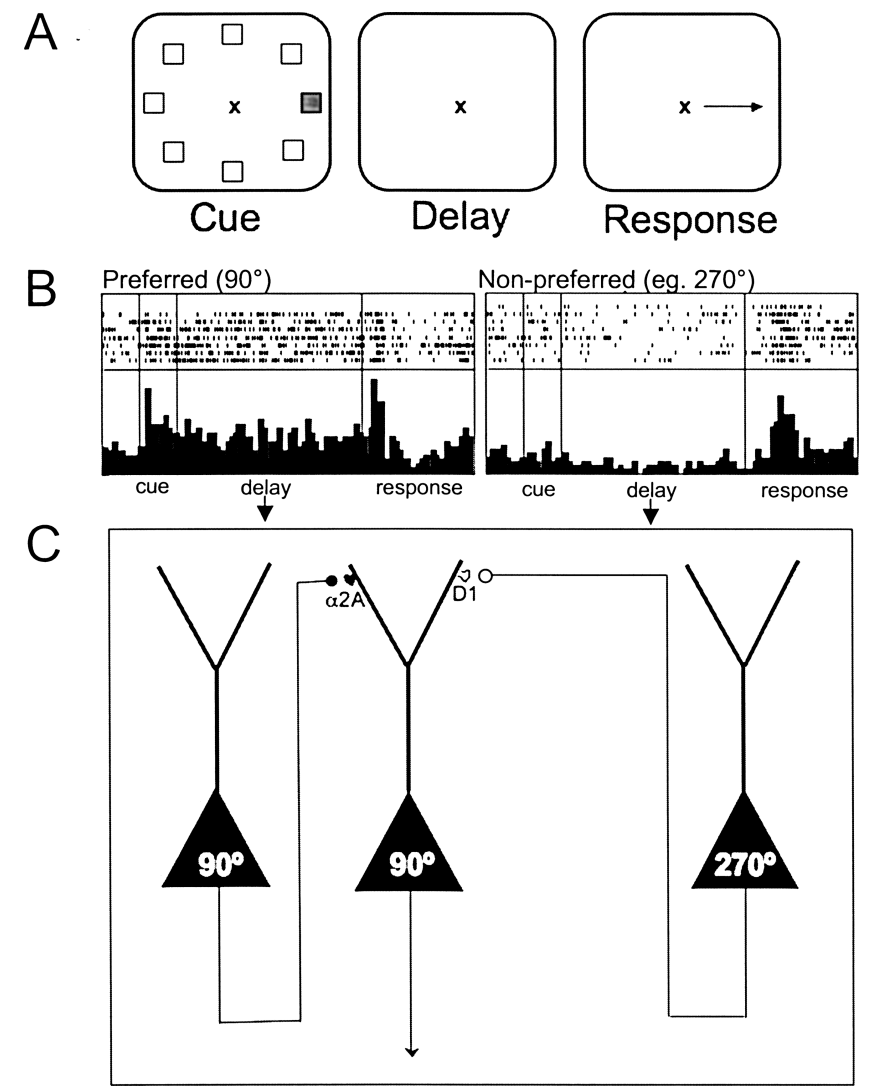

Figure 1. Spatial tuning of PFC networks by DA D1 and NE $\alpha 2 a$ receptors. $(A)$ Schematic representation of oculomotor delayed response (ODR) spatial working memory task. Monkeys are presented with a cue in a specified region of the visual field $\left(90^{\circ}\right)$. After a brief delay $(0-5 \mathrm{sec})$, the monkey must move its eyes to the previous cue location. (B) Neuronal firing of a single unit in the dIPFC during the delay period of the ODR task. The unit is "tuned" to $90^{\circ}$ (preferred direction) as indicated by increased delay-related firing following this stimulus. Firing of this unit is suppressed when the cue is presented in a nonpreferred region of the visual field (e.g., 270 $)$. (C) Schematic representation of spatial working memory network. Pyramidal cells with shared spatial preferences mutually excite each other to create persistent firing during the delay period. These network connections are strengthened by stimulation of $\alpha 2 a-A R s$ on PFC dendritic spines, reducing CAMP production and closing nearby $\mathrm{HCN}$ channels. Conversely, inputs from pyramidal neurons representing nonpreferred directions (particularly orthogonal directions) onto a different set of spines are suppressed via DA D1-R stimulation, which increases CAMP production. These actions likely occur through opening of $\mathrm{HCN}$ channels near the nonpreferred input (refer to Fig. 2B for signaling cascade). The combination of signal enhancement and noise reduction achieves precision in the network, thereby strengthening working memory.

al. 2005). Lesions of the dlPFC in humans result in characteristic "frontal" cognitive deficits in planning and executing organized sequences of behavior or speech as well as working memory impairment (Luria 1970; Luria et al. 1970; Baddeley et al. 2000; Fuster 2001). The ventral PFC performs similar functions in the affective realm. Lesions of the ventral and orbital cortex are characterized by the inability to inhibit inappropriate emotions, and the inability to flexibly regulate behavior based on the representation of future punishment or reward (Damasio et al. 1994; Dias et al. 1996). Consistent with this, the ventromedial PFC (vmPFC) has massive projections to the amygdala, ventral striatum, and hypothalamus (Ongur et al. 1998; Price 1999; Ghashghaei and Barbas 2002; Stefanacci and Amaral 2002; Ghashghaei et al. 2007). 
Anterior and medial portions of the PFC, including the anterior cingulate cortex (ACC), are also of particular relevance to mental illness. These areas are specialized for error and reality monitoring, which would include the ability to decipher internal versus external sources of stimulation (Carter et al. 1998; Bush et al. 2000; Rubia et al. 2003; Lutcke and Frahm 2008; Simons et al. 2008; Turner et al. 2008). Widespread circuits within the PFC are likely involved with such high-order decision-making and categorization. The contributions of these pathways to such processes are now under investigation (Muhammad et al. 2006; Lee et al. 2007; Freedman and Miller 2008).

In humans, the PFC shows hemispheric specialization, with the left PFC being central to language production (Broca's area), while the right PFC is especially important for behavioral inhibition. Impairments to the right inferior and lateral PFC produce a symptom profile of impaired impulse control and weaker sustained attention, while right anterior orbital lesions lead in increased engagement in risky behaviors (Woods and Knight 1986; Garavan et al. 1999; Rubia et al. 2003; Aron et al. 2004).

Neuropsychological, brain imaging, and post-mortem studies have helped to identify PFC subregions affected by specific mental illnesses. It should be noted that other brain areas, including the amygdala, hippocampus, and temporal cortices, have also been implicated in schizophrenia, bipolar disorder, and PTSD, and are reviewed elsewhere (e.g., Campbell and MacQueen 2006; Boyer et al. 2007; Frey et al. 2007; Gur et al. 2007; Liberzon and Sripada 2008). Given the scope of this review, we briefly highlight findings most relevant to PFC dysfunction in these illnesses.

\section{Schizophrenia}

Schizophrenia is a multidimensional disorder resulting in alterations to thought, mood, and behavior. Psychotic symptoms are characterized by impairments in the perception of reality including delusions and hallucinations. Disorganized thought, speech, and behavior, and flattened affect or avolition are also prominent symptoms (American Psychological Association 2000). Impaired cognitive functioning is a fundamental feature of schizophrenia, and impoverished executive abilities contribute to the poor functional outcome of patients (Ragland et al. 2007). Numerous studies indicate that dysfunction of the dIPFC underlies schizophrenia pathophysiology (e.g., Goldman-Rakic 1994, 1995a, 1999; Lewis 1995; Lewis and Anderson 1995; GoldmanRakic and Selemon 1997; Glantz and Lewis 2000). Early studies by Weinberger and colleagues using the Wisconsin Card Sorting Task (WCST), which measures concept formation, working memory, cognitive flexibility, and feedback monitoring, found reduced cerebral blood flow to the dIPFC in schizophrenia patients compared with healthy control subjects (Berman et al. 1986, 1988; Weinberger et al. 1986, 1988). More recent fMRI studies examining distinct components of this task, such as working memory, indicate reduced activity of the dlPFC in schizophrenia patients, which may explain performance deficits in these operations (e.g., Callicott et al. 1998; Barch et al. 2001; Perlstein et al. 2001).

While the dIPFC is most widely implicated with schizophrenia, recent studies indicate a role for other subregions of the PFC in symptomology. Hypoactivity of the ACC is observed in patients for a variety of inhibitory tasks (e.g., Rubia et al. 2001). In addition to impaired error monitoring (Carter et al. 2001; Kerns et al. 2005), a recent study has linked underactivity of the medial anterior and right lateral PFC to altered associative abilities and proneness to psychosis (Simons et al. 2008). Furthermore, auditory hallucinations may arise from inadequate corollary discharge from the PFC to Wernicke's area during inner speech (Ford and Mathalon 2005), i.e., inadequate tagging that a voice is internally generated. Taken together, these new data represent increasing links between PFC dysfunction, cognitive impairment, and the so-called "positive" symptoms of psychotic illness.

Structural imaging and post-mortem studies indicate significant alterations in fundamental PFC network substrates in schizophrenia patients. Studies by Lewis and colleagues found reduced axonal cartridges of chandelier GABAergic interneurons in the dlPFC of schizophrenia patients (Woo et al. 1998; Volk and Lewis 2002) that may impair tuning of PFC networks. Reduced glutamate receptor binding is also observed in the dlPFC of schizophrenia patients (Konradi and Heckers 2003), compromising the main currency of these recurrent excitatory networks. Structural imaging studies indicate deficits in dlPFC gray matter volume in schizophrenia (Sullivan et al. 1998; Gur et al. 2000), and associations between PFC gray matter density and clinical symptom ratings in schizophrenia patients have been identified, with reduced PFC volume predicting more severe symptoms (Gur et al. 2000). Gray matter reduction is thought to reflect loss of neuropil (e.g., Selemon et al. 1998; Selemon and Goldman-Rakic 1999; Selemon 2001) and, particularly, dendritic retraction and dendritic spine loss among pyramidal neurons, as post-mortem analyses indicate a pronounced reduction in dendritic spine density in superficial PFC pyramidal neurons (Lewis and Anderson 1995; Glantz and Lewis 2000, 2001). Importantly, PFC network operations are believed to be carried out within superficial layers (Goldman-Rakic 1990, 1995b). Since dendritic spines comprise the majority of excitatory cortical synapses (Gray 1959; for reviews, see Shepherd 1996; Sheng and Hoogenraad 2007), they represent a critical component of the excitatory circuitry underlying PFC operations.

\section{Bipolar disorder}

Bipolar disorder, also called manic-depressive illness, is characterized by recurrent fluctuations in affect and behavior. The clinical spectrum of bipolar disorder, as defined by the DSM-IV, includes two subtypes: Diagnosis of bipolar disorder I requires a manic episode (patients may have mixed manic and depressive episodes), and diagnosis of bipolar disorder II requires both depressive and hypomanic episodes (American Psychological Association 2000). The fluctuation in mood states within bipolar disorder provides the unique opportunity to observe changes in cognition and brain state while the same patient is in different phases of the illness. Manic patients are characterized by increased risk taking, distractibility, and reduced inhibition (American Psychological Association 2000). These deficits are associated with impaired right PFC function (Woods and Knight 1986; Garavan et al. 1999; Rubia et al. 2003; Aron et al. 2004). Neuropsychological studies indicate patients are also impaired in attention and reversal tasks during the depressed phase (Murphy et al. 1999; Murphy and Sahakian 2001), and past number of depressive episodes is predictive of poorer neurocognitive function (for review, see Bauer et al. 2003). Subsyndromal symptoms of impaired cognitive control and executive function, most notably attention and inhibition, persist during periods of remission in patients, suggesting that these impairments are inherent to the disease state (for reviews, see Phillips and Vieta 2007; Vieta and Phillips 2007).

Neuroimaging studies reveal alterations to the PFC in both the manic and depressed phases. Blumberg and colleagues (2003) have shown that during the depressive phase, patients demonstrate altered activity in the left vmPFC. This is consistent with the role of the left vmPFC in negative stimuli appraisal and depressed mood (Robinson et al. 1984), and is similar to alterations observed in patients with Major Depressive Disorder (Drevets et al. 1992). However, during the manic phase, bipolar patients exhibit underactivity of the ventral PFC, inferior PFC, and frontal 
pole in the right hemisphere (Blumberg et al. 1999, 2003, 2006). These results are consistent with the right PFC regulating attention and inhibitory processes and fit with the disinhibited mood and behaviors that characterize mania. Similar to schizophrenia, bipolar disorder is also associated with reduced PFC gray matter volume in regions where functional alterations are observed, particularly the ventral PFC (Lopez-Larson et al. 2002; Blumberg et al. 2006). Not surprisingly, reduced PFC volume predicts impaired performance on an attention task in acutely manic bipolar patients (Sax et al. 1999).

\section{PTSD}

PTSD is an anxiety disorder precipitated by an extreme stressor or traumatic event such as natural disaster, combat, or physical or sexual abuse (Francati et al. 2007). PTSD is characterized by intrusive and vivid re-experiencing of a trauma. Symptoms include enhanced memory for arousing events, flashbacks, hypervigilance, and impaired executive operations of the PFC (Yehuda et al. 1995; Orr 1997; Orr et al. 1997; Vasterling et al. 1998; Bremner et al. 1999a,b; Southwick et al. 1999; Golier and Yehuda 2002; Golier et al. 2002). PTSD is commonly associated with: overactivity of the noradrenergic/norepinephrine (NE) system arising from the locus coeruleus (LC), hyperactivation of the amygdala, and hypoactivation of the PFC (for reviews, see Francati et al. 2007; Bremner et al. 2008). Medial PFC volume is reduced and underactive during symptomatic states, and these medial PFC deficits are inversely proportional to symptom severity (for review, see Shin et al. 2006). Underactivity of the PFC likely contributes to patients' inability to suppress traumatic memories and to modulate amygdala and LC activation, resulting in anxiety and hypervigilance. Since dysfunction of the medial PFC is related to impaired error and reality monitoring (Carter et al. 2001; Simons et al. 2008), these findings may also serve to explain flashbacks, where patients confuse vivid memories with reality.

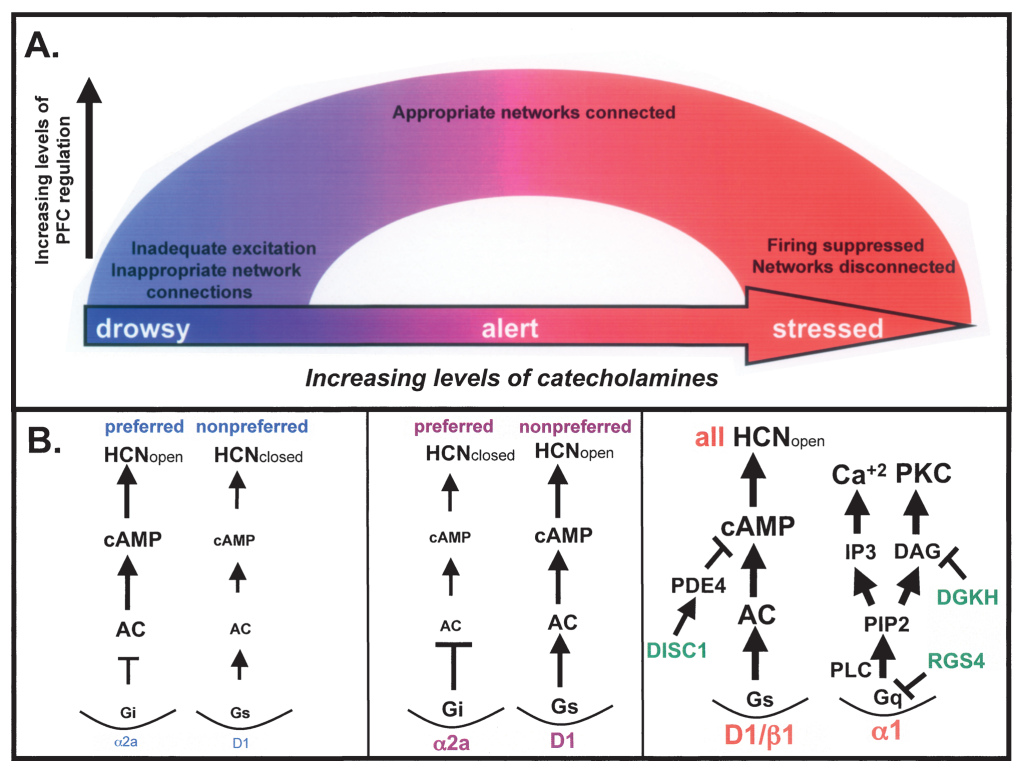

Figure 2. Catecholamine and intracellular signaling events modulating PFC function according to state of arousal. $(A)$ Catecholamines exert an inverted $U$ dose response on PFC function whereby either too little or too much is detrimental to cognitive function, and particularly working memory performance. Catecholamines are released in the PFC according to state of alertness, with increasing levels of release occurring with increasing arousal. PFC networks are optimally tuned when moderate levels of NE and DA are available, engaging $\alpha 2 a-A R s$ and moderately stimulating D1-Rs, respectively. Inadequate stimulation of these receptors (e.g., drowsiness, or under conditions of depletion, such as Parkinson's Disease) impairs PFC regulation of behavior, thought, and affect. In contrast, excessive NE or DA release, which is associated with stress and PTSD, impairs PFC cognitive functioning and network operations via $\alpha 1$-ARs, $\beta 1$-ARs, and excessive DA D1-R stimulation. Thus, the PFC must have precise regulation of catecholamines for proper PFC function. $(B)$ The intracellular signaling mechanisms that mediate catecholamine actions in PFC, and their relationship to genetic linkages with schizophrenia and bipolar disorder, are indicated. With inadequate catecholamine release (e.g., drowsiness), spines receiving network connections from pyramidal cells with shared characteristics (preferred directions) would have inadequate $\alpha 2$-AR stimulation, leading to weakened (appropriate) network inputs via excessive cAMP-HCN signaling. Conversely, spines receiving network connections from pyramidal cells with dissimilar inputs (nonpreferred directions) would have inadequate D1-R stimulation, leading to strengthened inappropriate network inputs due to insufficient CAMP-HCN signaling in those spines. Thus, under drowsy conditions, a PFC neuron would have inappropriate network connectivity (left panel, blue). In contrast, under optimal levels of catecholamine stimulation, $\alpha 2$-AR stimulation would strengthen preferred network inputs through inhibition of CAMP-HCN signaling, while moderate levels of D1-R stimulation would weaken nonpreferred inputs and help to tune the neuron appropriately. Under these conditions, the cell would have optimal enhancement of "signal" and suppression of "noise" (middle panel, pink). However, with high levels of DA and NE released during stress, excessive CAMP-HCN signaling initiated by high levels of D1-R and $\beta 1-A R$ stimulation would disconnect all network inputs, leading to loss of firing. Similarly, high levels of NE would engage $\alpha 1$-ARs, activating $\mathrm{PI}-\mathrm{PKC}$ signaling, suppressing cell firing, and impairing working memory. Increased intracellular $\mathrm{Ca}^{2+}$ may impair PFC function by opening SK channels or activating kinases such as CAMKII and PKC (right panel, red). Molecules associated with genetic alterations in serious mental illness are indicated (green). These molecules normally serve to inhibit intracellular stress pathways: cAMP signaling is inhibited by DISC1, PI signaling is inhibited by RGS4, and PKC signaling is inhibited by DAG Kinases including DGKH. DISC1 mutations are linked to schizophrenia and bipolar disorder, RGS4 mutations are linked to schizophrenia, and $D G K H$ mutations are linked to bipolar disorder. Alterations in these genes, and the associated proteins, would weaken endogenous regulation of stress pathways, perhaps accounting for patients' vulnerability to stress and their severe loss of PFC regulation of behavior, thought, and affect.

\section{Molecular regulation of the PFC}

The integrity of local working memory circuits is highly sensitive to PFC neurochemical state. Glutamate, GABA, and numerous neuromodulators critically contribute to PFC function (for review, see Arnsten and Robbins 2002). This review focuses on the influence of catecholamines on PFC function, as catecholamine signaling is directly relevant to the stress response as well as the pathophysiology and treatment of neuropsychiatric disorders.

It is well established that catecholamines exert an inverted $U$ dose response on working memory performance, whereby too much or too little DA or NE impairs spatial working memory and delay-related neuron firing (Fig. 2; Arnsten 2007). Catecholamines are likewise important for the attentional set-shifting properties of the lateral PFC. DA is needed to establish an attentional set (Crofts et al. 2001), and NE is needed to shift set (Tait et al. 2007). NE is also important for the operations of the ventrolateral PFC, including behavioral inhibition (Chamberlain et al. 2007) and conditional motor responding (Wang et al. 2004). In contrast, studies of the reversal operations of the orbital PFC indicate that serotonin is especially important to this region (Clarke et al. 2007), although more detailed manipulations indicate that catecholamines influence some orbital functions as well (e.g., Steere and Arnsten 1997). 
NE and DA are released in the PFC according to state of arousal, with low levels released during drowsy/bored conditions, moderate levels during alert conditions, and high levels during even mild, uncontrollable stress. Under optimal, alert conditions, NE and DA neurons have relatively low spontaneous firing, but fire to stimuli that are relevant and/or associated with reward, respectively (for reviews, see Berridge and Waterhouse 2003; Aston-Jones and Cohen 2005; Schultz 2007a,b). Neurons of the PFC project to NE and DA cells in brainstem and likely regulate this firing pattern under optimal conditions (Arnsten and Goldman-Rakic 1984; Gariano and Groves 1988; Aston-Jones et al. 1991; Sesack and Pickel 1992; Sara and Herve-Minvielle 1995; Shinba et al. 2000; Bouret and Sara 2004). In contrast, under conditions of psychological stress, the amygdala activates NE and DA cells and increases catecholamine release in the PFC (Goldstein et al. 1996). The amount of NE released engages different types of receptors: NE has highest affinity for $\alpha 2 \mathrm{a}$-ARs, lower affinity for $\alpha 1$-adrenoceptors ( $\alpha 1$-ARs), and lowest affinity for $\beta$ adrenoceptors ( $\beta$-ARs). These receptors have opposing effects on PFC function, with $\alpha 2$ a-ARs improving, and $\alpha 1$-ARs and $\beta 1$-ARs impairing, PFC function (for review, see Ramos and Arnsten 2006). Thus, PFC function is tightly coupled to arousal state due to powerful catecholamine actions in the PFC.

\section{Optimal regulation of working memory by catecholamines}

The pioneering work of Brozoski and Goldman-Rakic revealed the powerful influences of catecholamines on the cognitive operations of the dlPFC (Brozoski et al. 1979). This early study showed that depleting catecholamines in PFC was as destructive as lesioning the PFC. Although this study focused on DA, it is now known that blockade of either NE or DA actions has deleterious effects, and moderate $\alpha 2 \mathrm{a}-\mathrm{AR}$ and $\mathrm{D} 1$ receptor (D1-R) stimulation is required for optimal working memory performance (Sawaguchi and Goldman-Rakic 1991; Li et al. 1994). Electrophysiological studies in monkeys performing working memory tasks indicate that optimal levels of catecholamines are needed for the appropriate connectivity of PFC networks engaged in cognitive operations. As illustrated in Figure 1, moderate levels of NE strengthen the connectivity of network inputs from neurons with shared properties through stimulation of post-synaptic $\alpha 2 a-$ ARs (i.e., $\alpha 2 \mathrm{a}$-ARs enhance "signals" within the network), while optimal DA stimulation of D1-Rs weakens network connections with inappropriate inputs (i.e., D1-Rs decrease "noise" within the network).

Emerging data indicate a critical role for cAMP activation of Hyperpolarization Activation Cyclic Nucleotide Gated (HCN) cation channels in these gating functions. HCN channels are localized on the heads and necks of dendritic spines near incoming synapses in the superficial layers of monkey PFC, the layers that form the cortical-cortical networks (Wang et al. 2007). When the HCN channels are opened by the presence of cAMP, nearby synaptic inputs are shunted due to the reduction in membrane resistance (Wang et al. 2007). Thus, activation of cAMPHCN signaling weakens the network inputs onto that spine compartment. $\alpha 2 \mathrm{a}$-ARs are localized next to HCN channels on spines, and are thus ideally positioned to modulate the local concentration of cAMP near the channels via $\mathrm{G}_{i}$ inhibition of cAMP production (Fig. 2B). Electrophysiological studies have shown that $\alpha 2 \mathrm{a}-\mathrm{AR}$ stimulation increases network firing for preferred directions, and this improvement can be reversed by manipulations that increase or mimic cAMP (Wang et al. 2007). Conversely, blockade of $\alpha 2 \mathrm{a}$-ARs induces network collapse that can be rescued by blockade of HCN channels (Wang et al. 2007). Similar results have been observed at the behavioral level (Ramos et al. 2006; Wang et al. 2007).

In contrast, optimal D1-R stimulation helps to tune PFC microcircuits by suppressing cell responses to nonpreferred stimuli (e.g., spatial directions for which the microcircuit is not tuned) (Vijayraghavan et al. 2007). D1-Rs and $\alpha 2 a-A R s$ appear to be on different dendritic spines (C. Paspalas and A.F.T. Arnsten, unpubl.), suggesting they modulate different sets of network inputs. D1-R-mediated suppression of inputs occurs via stimulation of $\mathrm{G}_{s}$ proteins and subsequent increases in cAMP signaling (Fig. 2B; Vijayraghavan et al. 2007), and preliminary data indicate that this suppression occurs via opening of HCN channels (N.J. Gamo, M. Wang, and A.F.T. Arnsten, unpubl.). We have proposed that D1-R stimulation dynamically regulates the breadth of network tuning based on task demands (Vijayraghavan et al. 2007).

\section{High levels of catecholamine release during stress impair PFC function}

It is now clear that the deleterious effects of acute stress on PFC operations arise from excessive NE and DA release in the PFC (Deutch and Roth 1990; Rossetti et al. 1990; Finlay et al. 1995; Murphy et al. 1996; Birnbaum et al. 1999, 2004; Vijayraghavan et al. 2007). Under conditions of high arousal or stress, the amygdala excites brainstem nuclei to release high levels of DA and NE in the PFC (Goldstein et al. 1996). Excessive D1-R stimulation in PFC impairs working memory through cAMP signaling (Zahrt et al. 1997; Vijayraghavan et al. 2007), and electrophysiological studies show that high levels of D1-R stimulation suppress delayrelated cell firing via excessive cAMP actions, consistent with network collapse (Vijayraghavan et al. 2007). Preliminary evidence indicates that these deleterious actions can be prevented by blocking HCN channels (N.J. Gamo, M. Wang, and A.F.T. Arnsten, unpubl.). High levels of NE stimulation of $\beta 1$-AR may also contribute to excessive cAMP signaling and PFC cognitive dysfunction (Ramos et al. 2005).

High levels of NE released during stress impair working memory and neuronal firing through stimulation of $\alpha 1$-ARs (Birnbaum et al. 1999, 2004). As shown in Figure 2B, $\alpha 1$-AR stimulation impairs PFC function through products of the phosphatidylinositol (PI) cascade (Garcia-Sainz 1993; Birnbaum et al. $1999,2004)$. Upon activation of the PI cascade, phospholipase C cleaves the phospholipid phosphatidylinositol bisphosphate $\left(\mathrm{PIP}_{2}\right)$, generating membrane-bound diacylglycerol (DAG) and diffusible inositol 1, 4, 5-trisphosphate $\left(\mathrm{IP}_{3}\right)$. $\mathrm{IP}_{3}$ binds receptors on the endoplasmic reticulum, leading to release of calcium $\left(\mathrm{Ca}^{2+}\right) . \mathrm{Ca}^{2+}$-dependent kinases negatively influence PFC cognitive functions. Activation of $\mathrm{Ca}^{2+}$-calmodulin-dependent kinase II (CaMKII) and inhibition of the $\mathrm{Ca}^{2+}$-activated phosphatase, calcineurin, impair spatial working memory in the rat (Runyan et al. 2005; Dash et al. 2007). These actions may be mediated, in part, by the opening of small-conductance $\mathrm{Ca}^{2+}$-gated potassium channels (SK channels) that suppress neuronal firing (Hagenston et al. 2007; Brennan et al. 2008). Protein kinase C (PKC) is cooperatively activated by $\mathrm{Ca}^{2+}$ and DAG. PKC activation suppresses delay-related firing of PFC neurons in monkeys performing a working memory task, and impairs spatial working memory performance in both rats and monkeys (Birnbaum et al. 2004; Runyan et al. 2005). Thus, both products of the stress-activated PI cascade have deleterious effects on PFC functioning.

\section{The effects of chronic stress on the PFC}

Studies of the effects of chronic stress may provide valuable insight regarding the consequences of sustained neurochemical disruption in mental illness. Chronic stress increases NE responsivity within the PFC (Finlay et al. 1995, 1997; Miner et al. 2006), which likely leads to sustained, elevated PI-PKC signaling and suppression of working memory networks. Conversely, chronic stress exposure has also been linked to depletions in DA within the rat PFC (Mizoguchi et al. 2000), indicating that the neuro- 
chemical response to chronic stress is complex and does not necessarily scale proportionally with the effects of acute stress. Working memory performance following chronic stress declines for up to $10 \mathrm{~d}$ following the termination of stress (Mizoguchi et al. 2000). These enduring cognitive impairments suggest a sustained reorganization. Indeed, a variety of chronic stress paradigms induce structural alterations to rat medial PFC, which is critical for performance of spatial working memory tasks. These structural changes include dendritic spine loss and dendritic atrophy of layer II/III pyramidal neurons (Wellman 2001; Seib and Wellman 2003; Cook and Wellman 2004; Radley et al. 2004, 2006), similar to alterations in PFC gray matter observed in bipolar disorder and schizophrenia. Remodeling of the dendritic tree and gross anatomical changes to superficial PFC lamina are associated with cognitive performance following stress where decreased structural integrity of PFC neurons predicts PFC cognitive impairment in the rat (Cerqueira et al. 2005; Liston et al. 2006).

\section{Contrasts between the PFC, amygdala, and hippocampus}

The effects of stress on amygdala function and structure are opposite to those observed in the PFC (summarized in Fig. 3). High levels of catecholamines enhance amygdala operations; e.g., catecholamines strengthen fear conditioning and memory consolidation (Debiec and LeDoux 2004, 2006). Thus, memory of an event is improved when $\alpha 1$-AR and $\beta$-AR agonists are infused into the amygdala immediately after its occurrence (Ferry et al. 1999a,b,c; McGaugh and Roozendaal 2002; Roozendaal et al. 2002, 2004a,b). High levels of NE also enhance memory consolidation through actions in the hippocampus (Hopkins and Johnston 1988; Roozendaal et al. 2004b). For example, $\beta$-AR stimulation increases plasticity, synapse strength, and excitability of hip- pocampal neurons (Hopkins and Johnston 1988; Lancaster et al. 2001; Hu et al. 2007). The effects of stress on hippocampus- and amygdala-dependent memory operations are reviewed elsewhere (e.g., Sandi and Pinelo-Nava 2007). Differences between the amygdala, hippocampus, and PFC are also evident following chronic stress. While chronic stress exposure induces dendritic retraction in PFC, it causes dendritic hypertrophy and increased spine density in principal neurons of the amygdala (Mitra et al. 2005) and facilitates fear conditioning (Conrad et al. 1999), suggesting these structural elaborations also enhance amygdala function. The hippocampus exhibits an intermediate response, with dendritic retraction observed after prolonged stress exposure (Watanabe et al. 1992; Magarinos and McEwen 1995). The PFC shows structural impairments following shorter and milder stress exposure than that required for hippocampal structural changes (Magarinos and McEwen 1995; Brown et al. 2005), indicating the profound vulnerability of the PFC to stress.

The opposing effects of stress on PFC and amygdala function may have adaptive value (Arnsten 1998). In nonstressful conditions, the PFC tonically inhibits amygdala firing, suppressing anxiolytic behavior and supporting a state that favors goaldirected, controlled behavior (Jaskiw and Weinberger 1990; Jinks and McGregor 1997; Hariri et al. 2000, 2003). Under conditions of stress, operations of the amygdala are facilitated, increasing the likelihood that the "present danger" will be remembered and avoided in the future, and helping the animal organize and execute an efficient behavioral response to the fearful or stressful stimuli. Since stressful conditions disengage the PFC and memory retrieval mechanisms, resources can be devoted to these more instinctive, rapid responses to the immediate stressor. This stress response system can also lead to maladaptive changes (for a review of the role of the hippocampus in stress dysregulation and mental illness, see Phillips et al. 2006). The amygdala plays a critical role in stress-induced increases in catecholamine release within the PFC (Goldstein et al. 1996). This would lead to further deterioration of top-down regulation by PFC and an increasingly amygdala-centric mode of processing. Dysregulation of catecholamine signaling and PFC and amygdala structure and function are central to PTSD and reflect the deleterious consequences of this feed-forward stress response system.

\section{Genetics of severe mental illness}

Most mental illnesses are considered polygenetic, where a variety of genes interact or contribute to disease pathophysiology. This complexity has eluded attempts to find a single "key" genetic variable that substantially predicts or contributes to a psychiatric disorder. Due to the small effect of individual genes, the heterogeneity of illnesses, and methodological and statistical variations, there are many conflicting reports on the involvement of specific genes in specific disorders. Despite these limitations, uncovering genes involved in schizophrenia and bipolar disorder carry the promise of improving our understanding of these illnesses. Indeed, some of the most consistent evidence of both 
genetic linkage and association in schizophrenia and bipolar disorder involve genes that may directly impact PFC function. Several of these genes play a role in cortical development, neuroprotection (BDNF), and glutamate signaling, and these important genetic factors are reviewed elsewhere (e.g., Craddock et al. 2005; Owen et al. 2005, Tan et al. 2007; van Haren et al. 2008).

Another common genetic alteration, a single nucleotide polymorphism in the gene encoding for catechol-O-methyl transferase (COMT), may influence the risk for schizophrenia (for reviews, see Craddock et al. 2006; Turnbridge et al. 2006). COMT is an extracellular enzyme involved in the degradation of catecholamines, and particularly DA in the PFC (e.g., Turnbridge et al. 2006). The substitution of methionine for valine weakens the enzymatic degradation of DA, and shifts the D1 inverted U rightward (e.g., Nolan et al. 2004; Turnbridge et al. 2004, 2006; Winterer and Weinberger 2004). This substitution influences PFC cognitive abilities in both normal individuals (e.g., Nolan et al. 2004; Turnbridge et al. 2004) and patients (e.g., Egan et al. 2001). Numerous studies have investigated the association of COMT with mental illness and particularly schizophrenia. COMT is located on chromosome 22q11, a susceptibility locus for schizophrenia (Coon et al. 1994) and bipolar disorder (Badner and Gerson 2002). Indeed, there is evidence that the COMT valine variation is a weak risk factor for schizophrenia (Egan et al. 2001; Glatt et al. 2003), although such studies have produced mixed results (e.g., Munafo et al. 2005). However, given the scope of this review, it is not possible to adequately cover the progress and discrepancies within these fields. Instead, we will focus on findings relevant to the intracellular regulation of the PFC stress response.

Several of the genes most consistently altered in serious mental illness encode intracellular signaling molecules that inhibit stress pathways in PFC. These genes include Disrupted in Schizophrenia 1, (DISC1), which regulates cAMP signaling, and two molecules that suppress PI signaling: Regulator of G-Protein Signaling 4, (RGS4), and Diacylglycerol Kinase $\eta(D G K H)$. Mutations leading to loss of adequate function of these genes would weaken the "molecular brakes" on the PFC stress response, potentially leading to structural changes, cognitive deficits, and impoverished top-down regulation of the amygdala and other brain regions (genes are indicated in green in Fig. 2B). These genetic weaknesses may explain why stress is so poorly tolerated in these patient populations and why stressful life events often precipitate illness episodes and increase symptom severity.

\section{$\mathrm{DISCl}$}

Several independent genetic association and linkage studies indicate that DISC1 is a major susceptibility gene for schizophrenia, and some evidence also supports a role for DISC1 in bipolar disorder, as well (Millar et al. 2000, 2004, 2005; Blackwood and Muir 2004; Maeda et al. 2006; Mackie et al. 2007; Chubb et al. 2008). Alterations in DISC1 are associated with impairments in cognitive function in both schizophrenia patients and healthy individuals (Blackwood et al. 2001; Blackwood and Muir 2004; Cannon et al. 2005; Chubb et al. 2008). It has since been shown that DISC1 encodes a scaffolding protein (DISC1) that regulates cortical development (Hikida et al. 2007) and regulates cAMP signaling in the mature brain. DISC1 interacts with phosphodiesterase 4B (PDE4B) to increase the hydrolysis of cAMP under conditions of high cAMP concentrations (Millar et al. 2004, 2005). Thus, it is likely that impaired DISC1 function would lead to overactivation of cAMP-HCN signaling (Wang et al. 2007), explaining DISC1-related cognitive deficits in patients. Interestingly, DISC1 alterations are also implicated in structural changes to the PFC. Cannon and colleagues (2005) found that DISC1 mutations are associated with decreased PFC gray matter volume in schizophrenia patients. A mechanistic hypothesis for the con- tribution of DISC1 to PFC structural alterations is that sustained weakening of a synapse due to increased cAMP-HCN signaling may result in destruction of the synapse and elimination of dendritic spines (Yuste and Denk 1995; Yuste and Bonhoeffer 2001; Yuste and Majewska 2001; Okamoto et al. 2004; Zhou et al. 2004) and/or dendritic arbors, leading to observations of reduced neuropil volume.

\section{RGS4}

RGS4 belongs to a family of regulatory molecules that act as GTPase activating proteins (GAPs) for heterotrimeric $G_{\alpha}$ proteins, which drive $G_{\alpha}$ subunits into the inactive GDP-bound form, thereby decreasing their activity. In a study of over 7800 genes among six independent schizophrenia patients, RGS4 was found to be the most consistently altered transcript in the PFC of schizophrenia patients (Mirnics et al. 2001). It should be noted that there have been failed attempts to replicate an association between RGS4 alterations and schizophrenia (e.g., Sobell et al. 2005). There are a variety of factors that may explain discrepant findings including sample size, diagnostic criteria, population structure and statistical analysis, reporting measures, and the likelihood that schizophrenia has a heterogeneous etiology. However, subsequent findings support a role for RGS4 in both symptomology and pathophysiology. For example, a postmortem study found significantly lower mRNA and protein levels in the dlPFC of schizophrenia patients compared with healthy controls (Erdely et al. 2006), and RGS4 SNPs predicted poorer performance on clinical ratings scales in a recent study performed in a population of Han-Chinese schizophrenia patients (Lane et al. 2008).

While RGS4 does not appear to be selective for a single heterotrimeric $\mathrm{G}$ protein, the most consistent evidence is for RGS4 inhibiting $\mathrm{G}_{q}$ and $\mathrm{Ca}^{2+}$ signaling (Rogers et al. 2001; Tovey and Willars 2004; Snabaitis et al. 2005; Hao et al. 2006; Ladds et al. 2007). Moreover, GAPs such as RGS4 are critical for the regulation of PI-PKC-linked $G_{q}$ proteins, which have low intrinsic GTPase activity compared with $\mathrm{G}_{s}$ or $\mathrm{G}_{i}$ proteins (Hamm and Gilchrist 1996). Interestingly, RGS4 is also altered following chronic and acute stress exposure and amphetamine administration in rats (Ni et al. 1999; Schwendt et al. 2006). Thus, one may speculate that the loss of RGS4 in the PFC of patients with schizophrenia would increase PI signaling during stress exposure, leading to suppressed neuronal firing and loss of PFC cognitive abilities.

\section{$D G K H$}

$D G K H$ encodes the $\eta$ isoform of DAG Kinase (DGK). DGKs are a family of lipid kinases that catalyze the conversion of DAG to phosphatidic acid, thereby leading to reductions in DAG. DAG is a necessary cofactor for many isoforms of PKC; thus, DGKs are key regulators of PKC activation. A genome-wide association study, which examined over 500,000 genetic polymorphisms in independent samples, found that mutations in $D G K H$ are most robustly linked to bipolar disorder (Baum et al. 2008), and this finding has now been replicated in a separate, large sample (Wellcome Trust Case Control Consortium 2007). These genetic findings are consistent with numerous lines of evidence linking dysregulation of the PKC signaling cascade to bipolar disorder, and particularly mania (Friedman et al. 1993; Wang and Friedman 1996; Hahn and Friedman 1999; Manji and Lenox 1999; Manji et al. 1999; Wang et al. 1999, 2001; Arnsten and Manji 2008). Reduced DGK activity through mutations in $D G K H$ provides a potential mechanism for PKC dysregulation in bipolar disorder. Weakened inhibition of PKC signaling in bipolar disorder is consistent with stress precipitating manic episodes (Hammen and Gitlin 1997), and with PFC hypofunctioning in bipolar patients in the manic state (Blumberg et al. 1999). 


\section{Treatments for mental illness normalize PFC stress pathways}

Treatments for schizophrenia and bipolar disorder directly or indirectly modulate stress-related PFC signaling cascades, potentially correcting for the loss of adequate RGS4, DISC1, or DGK function. Atypical antipsychotics (e.g., olanzipine, risperidone, clozapine) block $\alpha 1$-ARs and 5HT2a receptors (Peroutka and Synder 1980; Cohen and Lipinski 1986; Dwivedi and Pandey 1999; Svensson 2003), thereby reducing PI-PKC signaling. DISC1 is increased in the frontal cortex following antipsychotic treatment (Chiba et al. 2006; Mackie et al. 2007), suggesting antipsychotic treatment may also help to regulate cAMP. Consistent with these actions, functional imaging studies indicate that chronic treatment with atypical antipsychotics can normalize PFC function in schizophrenia patients (Surguladze et al. 2007), and both schizophrenia and bipolar patients show improvements in measures of executive functioning, including working memory, following risperidone treatment (Harvey et al. 2005, 2007).

Treatments for mania inhibit PKC signaling, a finding first noted by Manji and colleagues (Manji and Lenox 1999; Manji et al. 1999). Chronic treatment with the antimanic agents lithium or valproate significantly reduce PKC activity and alter PKC distribution in bipolar patients and within the rat cortex (Manji and Lenox 1999; Manji et al. 1999, 2001; Chen et al. 2000; Wang et al. 2001; Manji and Chen 2002; Friedman et al. 2004; Hahn et al. 2005). There is indirect evidence that PKC activity plays a role in PFC structural alterations, as well. PFC gray matter loss in bipolar and schizophrenia patients is reversed by chronic lithium or valproate treatments (Blumberg et al. 2006; Bearden et al. 2007; Nakamura et al. 2007), and rodent studies indicate that chronic lithium treatment counteracts stress-induced plasticity in the hippocampus (Wood et al. 2004).

Finally, the medications used to treat PTSD are consistent with our understanding of the neurobiology of PTSD symptoms. As summarized above, PTSD is associated with high levels of NE release, which engage $\alpha 1$-ARs and $\beta$-ARs, thereby impairing PFC function and enhancing amygdala function (summarized in Fig. 3). Accordingly, effective treatments for PTSD include prazosin, an $\alpha 1$-AR antagonist, and possibly propranolol, a $\beta$-AR blocker (for review, see Strawn and Geracioti Jr. 2007). $\beta$-AR blockade is most effective when administered immediately following the trauma (Pitman et al. 2002; Debiec and LeDoux 2006). These acute effects may interfere with amygdala operations including memory consolidation and the immediate sensitization of stress pathways. In contrast, $\alpha 1-\mathrm{AR}$ antagonism is beneficial even in patients with established PTSD symptoms (Peskind et al. 2003; Raskind et al. 2003; Taylor et al. 2006). Prazosin improves symptoms of intrusive re-experiencing of the trauma and reduces psychological distress in response to trauma related cues (Raskind et al. 2003; Taylor et al. 2006; Strawn and Geracioti Jr. 2007). These beneficial effects likely reflect strengthened PFC modulation of amygdala and brain activity.

\section{Summary}

Symptoms of schizophrenia, bipolar disorder, and PTSD involve weakened PFC regulation of thought, emotion, and action. Exposure to stress exacerbates these symptoms in patients and reproduces aspects of PFC cognitive impairments in animals. The last decade has seen unprecedented advancements in our understanding of the molecular mechanisms of stress as well as the molecular and genetic correlates of mental illness. It is now clear that stress-induced catecholamine elevations impair PFC integrity, and particularly working memory function, by disconnecting local networks. Excessive DA stimulation of D1-Rs disconnects PFC networks via cAMP-HCN intracellular signaling, and excessive NE stimulation of $\alpha 1$-AR impairs prefrontal function via PI-PKC intracellular signaling.

Emerging genetic and genomic research indicates genetic weaknesses in the endogenous regulation of cAMP-HCN and PIPKC pathways in bipolar disorder and schizophrenia. Further studies in animals are required to assess whether such genetic weaknesses confer increased vulnerability to stress via the pathways described herein. NE overactivation is also implicated in the pathophysiology of PTSD. Dysregulation of these stress-related pathways likely explains patients' profound vulnerability to life stressors and characteristic PFC impairments. Animal studies of chronic stress may be helpful in understanding the effects of sustained dysregulation of stress-related in pathways in these disorders. Chronic dysregulation of stress pathways may lead to further elevations in catecholamine release within the PFC via enhancing amygdala processing. Recent rodent studies also indicate that chronic exposure to stress compromises critical structural components of PFC circuitry. Similar mechanisms may underlie illness and stress-related PFC structural impairments.

It is immensely encouraging that genetic and molecular research implicates common pathways in the pathophysiology of several of the most complex, poorly understood, and debilitating psychiatric illnesses. These intersections should herald new approaches for neurobiological and translational research. The immediate implications for developing novel therapies are clear: While the mainstay treatments for bipolar disorder and schizophrenia are likely effective through inhibiting aspects of these stress-related pathways, thereby interrupting this feed-forward cycle, new treatments that directly and specifically target PKC carry the promise of increased efficacy and reduced side effects.

\section{Acknowledgments}

Several of the studies discussed in this review were supported by NIH Conte Center grant P50MH068789 and NIH grant 1RL1AA017536-01 as part of Consortium U54RR024350-01 to A.F.T.A.

\section{References}

American Psychological Association. 2000. Diagnostic and statistical manual of mental disorders, 4th edition (DSM-IV). American Psychiatric Press, Inc., Washington, DC.

Arnsten, A.F. 1998. The biology of being frazzled. Science 280: $1711-1712$.

Arnsten, A.F. 2007. Catecholamine and second messenger influences on prefrontal cortical networks of "representational knowledge": A rational bridge between genetics and the symptoms of mental illness. Cereb. Cortex 17: i6-i15. doi: 10.1093/cercor/bhm033.

Arnsten, A.F. and Goldman-Rakic, P.S. 1984. Selective prefrontal cortical projections to the region of the locus coeruleus and raphe nuclei in the rhesus monkey. Brain Res. 306: 9-18.

Arnsten, A.F.T. and Manji, H.K. 2008. Mania: A rational neurobiology. Future Neurol. 3: 125-131.

Arnsten, A.F.T. and Robbins, T.W. 2002. Neurochemical regulation of prefrontal cortical function in humans and animals. In The frontal lobes (eds. D. Stuss and R. Knight), pp. 51-84. Oxford University Press, New York.

Aron, A.R., Robbins, T.W., and Poldrack, R.A. 2004. Inhibition and the right inferior frontal cortex. Trends Cogn. Sci. 8: 170-177.

Aston-Jones, G. and Cohen, J.D. 2005. An integrative theory of locus coeruleus-norepinephrine function: Adaptive gain and optimal performance. Annu. Rev. Neurosci. 28: 403-450.

Aston-Jones, G., Shipley, M.T., Chouvet, G., Ennis, M., van Bockstaele, E., Pieribone, V., Shiekhattar, R., Akaoka, H., Drolet, G., Astier, B., et al. 1991. Afferent regulation of locus coeruleus neurons: Anatomy, physiology and pharmacology. Prog. Brain Res. 88: 47-75.

Baddeley, A., Bueno, O., Cahill, L., Fuster, J.M., Izquierdo, I., McGaugh, J.L., Morris, R.G., Nadel, L., Routtenberg, A., Xavier, G., et al. 2000. The brain decade in debate: I. Neurobiology of learning and memory. Braz. J. Med. Biol. Res. 33: 993-1002.

Badner, J.A. and Gerson, E.S. 2002. Meta-analysis of whole-genome linkage scans of bipolar disorder and schizophrenia. Mol. Psychiatry 7: 405-411. 
Barbas, H., Medalla, M., Alade, O., Suski, J., Zikopoulos, B., and Lera, P. 2005. Relationship of prefrontal connections to inhibitory systems in superior temporal areas in the rhesus monkey. Cereb. Cortex 15: $1356-1370$.

Barch, D.M., Carter, C.S., Braver, T.S., Sabb, F.W., MacDonald 3rd, A., Noll, D.C., and Cohen, J.D. 2001. Selective deficits in prefrontal cortex function in medication-naive patients with schizophrenia. Arch. Gen. Psychiatry 58: 280-288.

Bauer, M., Alda, M., Priller, J., and Young, L.T. 2003. Implications of the neuroprotective effects of lithium for the treatment of bipolar and neurodegenerative disorders. Pharmacopsychiatry 36: 250-254.

Baum, A.E., Akula, N., Cabanero, M., Cardona, I., Corona, W., Klemens, B., Schulze, T.G., Cichon, S., Rietschel, M., Nothen, M.M., et al. 2008. A genome-wide association study implicates diacylglycerol kinase $\eta$ DGKH and several other genes in the etiology of bipolar disorder. Mol. Psychiatry 13: 197-207.

Bearden, C.E., Thompson, P.M., Dalwani, M., Hayashi, K.M., Lee, A.D., Nicoletti, M., Trakhtenbroit, M., Glahn, D.C., Brambilla, P., Sassi, R.B., et al. 2007. Greater cortical gray matter density in lithium-treated patients with bipolar disorder. Biol. Psychiatry 62: 7-16.

Berman, K.F., Zec, R.F., and Weinberger, D.R. 1986. Physiologic dysfunction of dorsolateral prefrontal cortex in schizophrenia. II. Role of neuroleptic treatment, attention, and mental effort. Arch. Gen. Psychiatry 43: $126-135$.

Berman, K.F., Illowsky, B.P., and Weinberger, D.R. 1988. Physiological dysfunction of dorsolateral prefrontal cortex in schizophrenia. IV. Further evidence for regional and behavioral specificity. Arch. Gen. Psychiatry 45: 616-622.

Berridge, C.W. and Waterhouse, B.D. 2003. The locus coeruleus-noradrenergic system: Modulation of behavioral state and state-dependent cognitive processes. Brain Res. Brain Res. Rev. 42: $33-84$.

Birley, J.L. and Brown, G.W. 1970. Crises and life changes preceding the onset or relapse of acute schizophrenia: Clinical aspects. $\mathrm{Br}$. $J$. Psychiatry 116: $327-333$

Birnbaum, S., Gobeske, K.T., Auerbach, J., Taylor, J.R., and Arnsten, A.F. 1999. A role for norepinephrine in stress-induced cognitive deficits: $\alpha$-1-adrenoceptor mediation in the prefrontal cortex. Biol. Psychiatry 46: $1266-1274$.

Birnbaum, S.G., Yuan, P.X., Wang, M., Vijayraghavan, S., Bloom, A.K., Davis, D.J., Gobeske, K.T., Sweatt, J.D., Manji, H.K., and Arnsten, A.F. 2004. Protein kinase C overactivity impairs prefrontal cortical regulation of working memory. Science 306: 882-884.

Blackwood, D.H. and Muir, W.J. 2004. Clinical phenotypes associated with DISC1: A candidate gene for schizophrenia. Neurotox. Res. 6: $35-41$.

Blackwood, D.H., Fordyce, A., Walker, M.T., St Clair, D.M., Porteous, D.J., and Muir, W.J. 2001. Schizophrenia and affective disorders-cosegregation with a translocation at chromosome 1q42 that directly disrupts brain-expressed genes: Clinical and P300 findings in a family. Am. J. Hum. Genet. 69: 428-433.

Blumberg, H.P., Stern, E., Ricketts, S., Martinez, D., de Asis, J., White, T., Epstein, J., Isenberg, N., McBride, P.A., Kemperman, I., et al. 1999. Rostral and orbital prefrontal cortex dysfunction in the manic state of bipolar disorder. Am. J. Psychiatry 156: 1986-1988.

Blumberg, H.P., Charney, D.S., and Krystal, J.H. 2002. Frontotemporal neural systems in bipolar disorder. Semin. Clin. Neuropsychiatry 7: 243-254.

Blumberg, H.P., Leung, H.C., Skudlarski, P., Lacadie, C.M., Fredericks, C.A., Harris, B.C., Charney, D.S., Gore, J.C., Krystal, J.H., and Peterson, B.S. 2003. A functional magnetic resonance imaging study of bipolar disorder: State- and trait-related dysfunction in ventral prefrontal cortices. Arch. Gen. Psychiatry 60: 601-609.

Blumberg, H.P., Krystal, J.H., Bansal, R., Martin, A., Dziura, J., Durkin, K., Martin, L., Gerard, E., Charney, D.S., and Peterson, B.S. 2006. Age, rapid-cycling, and pharmacotherapy effects on ventral prefrontal cortex in bipolar disorder: A cross-sectional study. Biol. Psychiatry 59: 611-618.

Botvinick, M.M., Braver, T.S., Barch, D.M., Carter, C.S., and Cohen, J.D. 2001. Conflict monitoring and cognitive control. Psychol. Rev. 108: $624-652$.

Bouret, S. and Sara, S.J. 2004. Reward expectation, orientation of attention and locus coeruleus-medial frontal cortex interplay during learning. Eur. J. Neurosci. 20: 791-802.

Boyer, P., Phillips, J.L., Rousseau, F.L., and Ilivitsky, S. 2007 Hippocampual abnormailites and memory deficits: New evidence of a strong pathophysiological link in schizophrenia. Brain Res. Rev. 54: $92-112$.

Bremner, J.D., Krystal, J.H., Southwick, S.M., and Charney, D.S. 1995 Functional neuroanatomical correlates of the effects of stress on memory. J. Trauma. Stress 8: 527-553.
Bremner, J.D., Narayan, M., Staib, L.H., Southwick, S.M., McGlashan, T., and Charney, D.S. 1999a. Neural correlates of memories of childhood sexual abuse in women with and without posttraumatic stress disorder. Am. J. Psychiatry 156: 1787-1795.

Bremner, J.D., Staib, L.H., Kaloupek, D., Southwick, S.M., Soufer, R., and Charney, D.S. 1999b. Neural correlates of exposure to traumatic pictures and sound in Vietnam combat veterans with and without posttraumatic stress disorder: A positron emission tomography study. Biol. Psychiatry 45: 806-816.

Bremner, J.D., Elzinga, B., Schmahl, C., and Vermetten, E. 2008. Structural and functional plasticity of the human brain in posttraumatic stress disorder. Prog. Brain Res. 167: 171-186.

Brennan, A.R., Dolinsky, B., Vu, M.A., Stanley, M., Yeckel, M.F., and Arnsten, A.F. 2008. Blockade of IP3-mediated SK channel signaling in the rat medial prefrontal cortex improves spatial working memory. Learn. Mem. 15: 93-96.

Brown, G.W. and Birley, J.L. 1968. Crises and life changes and the onset of schizophrenia. J. Health Soc. Behav. 9: 203-214.

Brown, S.M., Henning, S., and Wellman, C.L. 2005. Mild, short-term stress alters dendritic morphology in rat medial prefrontal cortex. Cereb. Cortex 15: 1714-1722.

Brozoski, T.J., Brown, R.M., Rosvold, H.E., and Goldman, P.S. 1979 Cognitive deficit caused by regional depletion of dopamine in prefrontal cortex of rhesus monkey. Science 205: 929-932.

Bush, G., Luu, P., and Posner, M.I. 2000. Cognitive and emotional influences in anterior cingulate cortex. Trends Cogn. Sci. 4: 215-222.

Callicott, J.H., Ramsey, N.F., Tallent, K., Bertolino, A., Knable, M.B., Coppola, R., Goldberg, T., van Gelderen, P., Mattay, V.S., Frank, J.A., et al. 1998. Functional magnetic resonance imaging brain mapping in psychiatry: Methodological issues illustrated in a study of working memory in schizophrenia. Neuropsychopharmacology 18: 186-196.

Campbell, S. and MacQueen, G. 2006. An update on regional brain volume differences associated with mood disorders. Curr. Opin. Psychiatry 19: 25-33.

Cannon, T.D., Hennah, W., van Erp, T.G., Thompson, P.M., Lonnqvist, J., Huttunen, M., Gasperoni, T., Tuulio-Henriksson, A., Pirkola, T., Toga, A.W., et al. 2005. Association of DISC1/TRAX haplotypes with schizophrenia, reduced prefrontal gray matter, and impaired shortand long-term memory. Arch. Gen. Psychiatry 62: 1205-1213.

Carter, C.S., Braver, T.S., Barch, D.M., Botvinick, M.M., Noll, D., and Cohen, J.D. 1998. Anterior cingulate cortex, error detection, and the online monitoring of performance. Science 280: 747-749.

Carter, C.S., MacDonald 3rd, A.W., Ross, L.L., and Stenger, V.A. 2001. Anterior cingulate cortex activity and impaired self-monitoring of performance in patients with schizophrenia: An event-related fMRI study. Am. J. Psychiatry 158: 1423-1428.

Cavada, C. and Goldman-Rakic, P.S. 1989. Posterior parietal cortex in rhesus monkey: II. Evidence for segregated corticocortical networks linking sensory and limbic areas with the frontal lobe. J. Comp. Neurol. 287: 422-445.

Cerqueira, J.J., Pego, J.M., Taipa, R., Bessa, J.M., Almeida, O.F., and Sousa, N. 2005. Morphological correlates of corticosteroid-induced changes in prefrontal cortex-dependent behaviors. J. Neurosci. 25: $7792-7800$.

Chamberlain, S.R., Del Campo, N., Dowson, J., Müller, U., Clark, L., Robbins, T.W., and Sahakian, B.J. 2007. Atomoxetine improved response inhibition in adults with attention deficit/hyperactivity disorder. Biol. Psychiatry 62: 977-984.

Chao, L.L. and Knight, R.T. 1998. Contribution of human prefrontal cortex to delay performance. J. Cogn. Neurosci. 10: 167-177.

Chen, G., Masana, M.I., and Manji, H.K. 2000. Lithium regulates PKC-mediated intracellular cross-talk and gene expression in the CNS in vivo. Bipolar Disord. 2: 217-236.

Chiba, S., Hashimoto, R., Hattori, S., Yohda, M., Lipska, B., Weinberger, D.R., and Kunugi, H. 2006. Effect of antipsychotic drugs on DISC1 and dysbindin expression in mouse frontal cortex and hippocampus. I. Neural Transm. 113: 1337-1346.

Chubb, J.E., Bradshaw, N.J., Soares, D.C., Porteous, D.J., and Millar, J.K. 2008. The DISC locus in psychiatric illness. Mol. Psychiatry 13: $36-64$.

Clarke, H.F., Walker, S.C., Dalley, J.W., Robbins, T.W., and Roberts, A.C. 2007. Cognitive inflexibility after prefrontal serotonin depletion is behaviorally and neurochemically specific. Cereb. Cortex 17: 18-27.

Cohen, B.M. and Lipinski, J.F. 1986. In vivo potencies of antipsychotic drugs in blocking $\alpha 1$ noradrenergic and dopamine D2 receptors: Implications for drug mechanisms of action. Life Sci. 39: 2571-2580.

Conrad, C.D., LeDoux, J.E., Magarinos, A.M., and McEwen, B.S. 1999. Repeated restraint stress facilitates fear conditioning independently of causing hippocampal CA3 dendritic atrophy. Behav. Neurosci. 113: $902-913$

Cook, S.C. and Wellman, C.L. 2004. Chronic stress alters dendritic morphology in rat medial prefrontal cortex. J. Neurobiol. 
60: $236-248$

Coon, H., Jense, S., Holik, J., Hoff, M., Myles-Worsley, M., Reimherr, F., Wender, P., Waldo, M., Freedman, R., Leppert, M., et al. 1994. Genomic scan for genes predisposing schizophrenia. Am. J. Med. Genet. 54: 59-71.

Corbetta, M. and Shulman, G.L. 2002. Control of goal-directed and stimulus-driven attention in the brain. Nat. Rev. Neurosci. 3: 201-215.

Craddock, N., O'Donovan, M.C., and Owen, M.J. 2005. The genetics of schizophrenia and bipolar disorder: Dissecting psychosis. J. Med. Genet. 42: 193-204.

Craddock, N., Owen, M.J., and O'Donocan, M.C. 2006. The Catechol-o-methyl transferase (COMT) gene as a candidate for psychiatric phenotypes: Evidence and lessons. Mol. Psychiatry 11: $446-458$.

Crofts, H.S., Dalley, J.W., Collins, P., van Denderen, J.C.M., Everitt, B.J., Robbins, T.W., and Roberts, A.C. 2001. Differential effects of 6-OHDA lesions of the prefrontal cortex and caudate nucleus on the ability to acquire an attentional set. Cereb. Cortex 11: 1015-1026.

Damasio, H., Grabowski, T., Frank, R., Galaburda, A.M., and Damasio, A.R. 1994. The return of Phineas Gage: Clues about the brain from the skull of a famous patient. Science 264: 1102-1105.

Dash, P.K., Moore, A.N., Kobori, N., and Runyan, J.D. 2007. Molecular activity underlying working memory. Learn. Mem. 14: 554-563.

Davidson, R.J. and Irwin, W. 1999. The functional neuroanatomy of emotion and affective style. Trends Cogn. Sci. 3: 11-21.

Debiec, J. and LeDoux, J.E. 2004. Disruption of reconsolidation but not consolidation of auditory fear conditioning by noradrenergic blockade in the amygdala. Neuroscience 129: 267-272.

Debiec, J. and LeDoux, J.E. 2006. Noradrenergic signaling in the amygdala contributes to the reconsolidation of fear memory: Treatment implications for PTSD. Ann. N. Y. Acad. Sci. 1071: 521-524.

Deutch, A.Y. and Roth, R.H. 1990. The determinants of stress-induced activation of the prefrontal cortical dopamine system. Prog. Brain Res. 85: 367-402 discussion 363-402.

Dias, R., Robbins, T.W., and Roberts, A.C. 1996. Dissociation in prefrontal cortex of affective and attentional shifts. Nature 380: 69-72.

Drevets, W.C., Videen, T.O., Price, J.L., Preskorn, S.H., Carmichael, S.T., and Raichle, M.E. 1992. A functional anatomical study of unipolar depression. J. Neurosci. 12: 3628-3641.

Dwivedi, Y. and Pandey, G.N. 1999. Effects of treatment with haloperidol, chlorpromazine, and clozapine on protein kinase C PKC and phosphoinositide-specific phospholipase C PI-PLC activity and on mRNA and protein expression of PKC and PLC isozymes in rat brain. J. Pharmacol. Exp. Ther. 291: 688-704.

Egan, M.F., Goldberg, T.E., Kolachana, B.S., Callicott, J.H., Mazzanti, C.M., Straub, R.E., Goldman, D., and Weinberger, D.R. 2001. Effect of COMT Val108/158 Met genotype on frontal lobe function and risk for schizophrenia. Proc. Natl. Acad. Sci. 98: 6917-6922.

Erdely, H.A., Tamminga, C.A., Roberts, R.C., and Vogel, M.W. 2006 Regional alterations in RGS4 protein in schizophrenia. Synapse 59: 472-479.

Ferry, B., Roozendaal, B., and McGaugh, J.L. 1999a. Basolateral amygdala noradrenergic influences on memory storage are mediated by an interaction between $\beta$ - and $\alpha 1$-adrenoceptors. J. Neurosci. 19: 5119-5123.

Ferry, B., Roozendaal, B., and McGaugh, J.L. 1999b. Involvement of $\alpha 1$-adrenoceptors in the basolateral amygdala in modulation of memory storage. Eur. I. Pharmacol. 372: 9-16.

Ferry, B., Roozendaal, B., and McGaugh, J.L. 1999c. Role of norepinephrine in mediating stress hormone regulation of long-term memory storage: A critical involvement of the amygdala. Biol. Psychiatry 46: 1140-1152.

Finlay, J.M., Zigmond, M.J., and Abercrombie, E.D. 1995. Increased dopamine and norepinephrine release in medial prefrontal cortex induced by acute and chronic stress: Effects of diazepam. Neuroscience 64: 619-628.

Finlay, J.M., Jedema, H.P., Rabinovic, A.D., Mana, M.J., Zigmond, M.J., and Sved, A.F. 1997. Impact of corticotropin-releasing hormone on extracellular norepinephrine in prefrontal cortex after chronic cold stress. J. Neurochem. 69: 144-150.

Ford, J.M. and Mathalon, D.H. 2005. Corollary discharge dysfunction in schizophrenia: Can it explain auditory hallucinations? Int. J. Psychophysiol. 58: 179-189.

Fowles, D.C. 1992. Schizophrenia: Diathesis-stress revisited. Annu. Rev. Psychol. 43: 303-336.

Francati, V., Vermetten, E., and Bremner, J.D. 2007. Functional neuroimaging studies in posttraumatic stress disorder: Review of current methods and findings. Depress. Anxiety 24: 202-218.

Freedman, D.J. and Miller, E.K. 2008. Neural mechanisms of visual categorization: Insights from neurophysiology. Neurosci. Biobehav Rev. 32: 311-329.

Frey, B.N., Andreazza, A.C., Nery, F.G., Martins, M.R., Quevedo, J., Soares, J.C., and Kapczinski, F. 2007. The role of the hippocampus in the pathophysiology of bipolar disorder. Behav. Pharmacol. 18: 419-430.

Friedman, E., Hoau Yan, W., Levinson, D., Connell, T.A., and Singh, H. 1993. Altered platelet protein kinase C activity in bipolar affective disorder, manic episode. Biol. Psychiatry 33: 520-525.

Friedman, S.D., Dager, S.R., Parow, A., Hirashima, F., Demopulos, C., Stoll, A.L., Lyoo, I.K., Dunner, D.L., and Renshaw, P.F. 2004. Lithium and valproic acid treatment effects on brain chemistry in bipolar disorder. Biol. Psychiatry 56: 340-348.

Fuster, J.M. 2001. The prefrontal cortex-an update: Time is of the essence. Neuron 30: 319-333.

Galea, S., Brewin, C.R., Gruber, M., Jones, R.T., King, D.W., King, L.A., McNally, R.J., Ursano, R.J., Petukhova, M., and Kessler, R.C. 2007. Exposure to hurricane-related stressors and mental illness after Hurricane Katrina. Arch. Gen. Psychiatry 64: 1427-1434.

Garavan, H., Ross, T.J., and Stein, E.A. 1999. Right hemispheric dominance of inhibitory control: An event-related functional MRI study. Proc. Natl. Acad. Sci. 96: 8301-8306.

Garcia-Sainz, J.A. 1993. $\alpha$ 1-adrenergic action: Receptor subtypes, signal transduction and regulation. Cell. Signal. 5: 539-547.

Gariano, R.F. and Groves, P.M. 1988. Burst firing induced in midbrain dopamine neurons by stimulation of the medial prefrontal and anterior cingulate cortices. Brain Res. 462: 194-198.

Ghashghaei, H.T. and Barbas, H. 2002. Pathways for emotion: Interactions of prefrontal and anterior temporal pathways in the amygdala of the rhesus monkey. Neuroscience 115: 1261-1279.

Ghashghaei, H.T., Hilgetag, C.C., and Barbas, H. 2007. Sequence of information processing for emotions based on the anatomic dialogue between prefrontal cortex and amygdala. Neuroimage 34: 905-923.

Glahn, D.C., Bearden, C.E., Cakir, S., Barrett, J.A., Najt, P., Serap Monkul, E., Maples, N., Velligan, D.I., and Soares, J.C. 2006. Differential working memory impairment in bipolar disorder and schizophrenia: Effects of lifetime history of psychosis. Bipolar Disord. 8: $117-123$.

Glantz, L.A. and Lewis, D.A. 2000. Decreased dendritic spine density on prefrontal cortical pyramidal neurons in schizophrenia. Arch. Gen. Psychiatry 57: 65-73.

Glantz, L.A. and Lewis, D.A. 2001. Dendritic spine density in schizophrenia and depression. Arch. Gen. Psychiatry 58: 203.

Glatt, S.J., Faraone, S.V., and Tsuang, M.T. 2003. Association between a functional catechol-o-methyltransferase gene polymorphism and schizophrenia meta-analysis of case-control and family-based studies. Am. J. Psychiatry 60: 889-896.

Goldman-Rakic, P.S. 1990. Cellular and circuit basis of working memory in prefrontal cortex of nonhuman primates. Prog. Brain Res. 85: 325-335 discussion 335-326.

Goldman-Rakic, P.S. 1994. Working memory dysfunction in schizophrenia. J. Neuropsychiatry Clin. Neurosci. 6: 348-357.

Goldman-Rakic, P.S. 1995a. Architecture of the prefrontal cortex and the central executive. Ann. N. Y. Acad. Sci. 769: 71-83.

Goldman-Rakic, P.S. 1995b. Cellular basis of working memory. Neuron 14: $477-485$.

Goldman-Rakic, P.S. 1999. The physiological approach: Functional architecture of working memory and disordered cognition in schizophrenia. Biol. Psychiatry 46: 650-661.

Goldman-Rakic, P.S. and Selemon, L.D. 1997. Functional and anatomical aspects of prefrontal pathology in schizophrenia. Schizophr. Bull. 23: 437-458.

Goldstein, L.E., Rasmusson, A.M., Bunney, B.S., and Roth, R.H. 1996. Role of the amygdala in the coordination of behavioral, neuroendocrine, and prefrontal cortical monoamine responses to psychological stress in the rat. J. Neurosci. 16: 4787-4798.

Golier, J. and Yehuda, R. 2002. Neuropsychological processes in post-traumatic stress disorder. Psychiatr. Clin. North Am. 25: 295-315.

Golier, J.A., Yehuda, R., Lupien, S.J., Harvey, P.D., Grossman, R., and Elkin, A. 2002. Memory performance in Holocaust survivors with posttraumatic stress disorder. Am. J. Psychiatry 159: 1682-1688.

Gray, E.G. 1959. Electron microscopy of synaptic contacts on dendrite spines of the cerebral cortex. Nature 183: 1592-1593.

Gur, R.E., Cowell, P.E., Latshaw, A., Turetsky, B.I., Grossman, R.I., Arnold, S.E., Bilker, W.B., and Gur, R.C. 2000. Reduced dorsal and orbital prefrontal gray matter volumes in schizophrenia. Arch. Gen. Psychiatry 57: 761-768.

Gur, R.E., Keshavan, M.S., and Lawrie, S.M. 2007. Deconstructing psychosis with human brain imaging. Schizophr. Bull. 33: 921-931.

Hagenston, A.M., Fitzpatrick, J.S., and Yeckel, M.F. 2007.

MGluR-mediated calcium waves that invade the soma regulate firing 
in layer V medial prefrontal cortical pyramidal neurons. Cereb. Cortex 18: 407-423.

Hahn, C.G. and Friedman, E. 1999. Abnormalities in protein kinase C signaling and the pathophysiology of bipolar disorder. Bipolar Disord. 1: 81-86.

Hahn, C.G., Umapathy, Wang, H.Y., Koneru, R., Levinson, D.F., and Friedman, E. 2005. Lithium and valproic acid treatments reduce PKC activation and receptor-G protein coupling in platelets of bipolar manic patients. J. Psychiatr. Res. 39: 355-363.

Hamm, H.E. and Gilchrist, A. 1996. Heterotrimeric G proteins. Curr. Opin. Cell Biol. 8: 189-196.

Hammen, C. and Gitlin, M. 1997. Stress reactivity in bipolar patients and its relation to prior history of disorder. Am. J. Psychiatry 154: $856-857$

Hao, J., Michalek, C., Zhang, W., Zhu, M., Xu, X., and Mende, U. 2006 Regulation of cardiomyocyte signaling by RGS proteins: Differential selectivity towards $\mathrm{G}$ proteins and susceptibility to regulation. J. Mol. Cell. Cardiol. 41: 51-61.

Hariri, A.R., Bookheimer, S.Y., and Mazziotta, J.C. 2000. Modulating emotional responses: Effects of a neocortical network on the limbic system. Neuroreport 11: 43-48.

Hariri, A.R., Mattay, V.S., Tessitore, A., Fera, F., and Weinberger, D.R. 2003. Neocortical modulation of the amygdala response to fearful stimuli. Biol. Psychiatry 53: 494-501.

Harvey, P.D., Rabinowitz, J., Eerdekens, M., and Davidson, M. 2005. Treatment of cognitive impairment in early psychosis: A comparison of risperidone and haloperidol in a large long-term trial. Am. J. Psychiatry 162: 1888-1895.

Harvey, P.D., Hassman, H., Mao, L., Gharabawi, G.M., Mahmoud, R.A., and Engelhart, L.M. 2007. Cognitive functioning and acute sedative effects of risperidone and quetiapine in patients with stable bipolar 1 disorder: A randomized, double-blind, crossover study. J. Clin. Psychiatry 68: 1186-1194.

Hikida, T., Jaaro-Peled, H., Seshadri, S., Oishi, K., Hookway, C., Kong, S., Wu, D., Xue, R., Andrade, M., Tankou, S., et al. 2007.

Dominant-negative DISC1 transgenic mice display schizophrenia-associated phenotypes detected by measures translatable to humans. Proc. Natl. Acad. Sci. 104: 14501-14506.

Hopkins, W.F. and Johnston, D. 1988. Noradrenergic enhancement of long-term potentiation at mossy fiber synapses in the hippocampus. J. Neurophysiol. 59: 667-687.

Hu, H., Real, E., Takamiya, K., Kang, M.G., Ledoux, J., Huganir, R.L., and Malinow, R. 2007. Emotion enhances learning via norepinephrine regulation of AMPA-receptor trafficking. Cell 131: $160-173$.

Jaskiw, G.E. and Weinberger, D.R. 1990. Ibotenic acid lesions of the medial prefrontal cortex potentiate FG-7142-induced attenuation of exploratory activity in the rat. Pharmacol. Biochem. Behav. 36: 695-697.

Jinks, A.L. and McGregor, I.S. 1997. Modulation of anxiety-related behaviours following lesions of the prelimbic or infralimbic cortex in the rat. Brain Res. 772: 181-190.

Kerns, J.G., Cohen, J.D., MacDonald 3rd, A.W., Johnson, M.K., Stenger, V.A., Aizenstein, H., and Carter, C.S. 2005. Decreased conflict- and error-related activity in the anterior cingulate cortex in subjects with schizophrenia. Am. J. Psychiatry 162: 1833-1839.

Kessler, R.C., Galea, S., Jones, R.T., and Parker, H.A. 2006. Mental illness and suicidality after Hurricane Katrina. Bull. World Health Organ. 84: 930-939

Kessler, R.C., Galea, S., Gruber, M.J., Sampson, N.A., Ursano, R.J., and Wessely, S. 2008. Trends in mental illness and suicidality after Hurricane Katrina. Mol. Psychiatry 13: 374-384.

Knight, R.T., Staines, W.R., Swick, D., and Chao, L.L. 1999. Prefrontal cortex regulates inhibition and excitation in distributed neural networks. Acta Psychol. (Amst.) 101: 159-178.

Konradi, C. and Heckers, S. 2003. Molecular aspects of glutamate dysregulation: Implications for schizophrenia and its treatment. Pharmacol. Ther. 97: 153-179.

Ladds, G., Goddard, A., Hill, C., Thornton, S., and Davey, J. 2007. Differential effects of RGS proteins on $G \alpha q$ and $G \alpha 11$ activity. Cell. Signal. 19: 103-113.

Lancaster, B., Hu, H., Ramakers, G.M., and Storm, J.F. 2001. Interaction between synaptic excitation and slow afterhyperpolarization current in rat hippocampal pyramidal cells. J. Physiol. 536: 809-823.

Lane, H.Y., Liu, Y.C., Huang, C.L., Chang, Y.C., Wu, P.L., Huang, C.H., and Tsai, G.E. 2008. RGS4 polymorphisms predict clinical manifestations and responses to risperidone treatment in patients with schizophrenia. J. Clin. Psychopharmacol. 28: 64-68.

Lee, D., Rushworth, M.F., Walton, M.E., Watanabe, M., and Sakagami, M. 2007. Functional specialization of the primate frontal cortex during decision making. J. Neurosci. 27: 8170-8173.

Lewis, D.A. 1995. Neural circuitry of the prefrontal cortex in schizophrenia. Arch. Gen. Psychiatry 52: 269-273 discussion 277-278. Lewis, D.A. and Anderson, S.A. 1995. The functional architecture of the prefrontal cortex and schizophrenia. Psychol. Med. 25: 887-894.

Li, B.M., Hu, X.T., and Mei, Z.T. 1994. Prefrontal injection of the $\alpha$ 2-adrenergic antagonist yohimbine impairs performance of a delayed GO/NO-GO task in monkeys. Sheng Li Xue Bao 46: 249-257.

Liberzon, I. and Sripada, C.S. 2008. The functional neuroanatomy of PTSD: A critical review. Prog. Brain Res. 167: 151-169.

Liston, C., Miller, M.M., Goldwater, D.S., Radley, J.J., Rocher, A.B., Hof, P.R., Morrison, J.H., and McEwen, B.S. 2006. Stress-induced alterations in prefrontal cortical dendritic morphology predict selective impairments in perceptual attentional set-shifting. $J$. Neurosci. 26: 7870-7874.

Lopez-Larson, M.P., DelBello, M.P., Zimmerman, M.E., Schwiers, M.L., and Strakowski, S.M. 2002. Regional prefrontal gray and white matter abnormalities in bipolar disorder. Biol. Psychiatry 52: 93-100.

Luria, A.R. 1970. The functional organization of the brain. Sci. Am. 222: $66-72$ passim

Luria, A.R., Simernitskaya, E.G., and Tubylevich, B. 1970. The structure of psychological processes in relation to cerebral organization. Neuropsychologia 8: 13-19.

Lutcke, H. and Frahm, J. 2008. Lateralized anterior cingulate function during error processing and conflict monitoring as revealed by high-resolution fMRI. Cereb. Cortex 18: 508-515.

Mackie, S., Millar, J.K., and Porteous, D.J. 2007. Role of DISC1 in neural development and schizophrenia. Curr. Opin. Neurobiol. 17: 95-102.

Maeda, K., Nwulia, E., Chang, J., Balkissoon, R., Ishizuka, K., Chen, H., Zandi, P., McInnis, M.G., and Sawa, A. 2006. Differential expression of disrupted-in-schizophrenia DISC1 in bipolar disorder. Biol. Psychiatry 60: 929-935.

Magarinos, A.M. and McEwen, B.S. 1995. Stress-induced atrophy of apical dendrites of hippocampal CA3c neurons: Comparison of stressors. Neuroscience 69: 83-88.

Manji, H.K. and Chen, G. 2002. PKC, MAP kinases and the bcl-2 family of proteins as long-term targets for mood stabilizers. Mol. Psychiatry (Suppl. 1) 7: 46-56.

Manji, H.K. and Lenox, R.H. 1999. Ziskind-Somerfeld Research Award. Protein kinase C signaling in the brain: Molecular transduction of mood stabilization in the treatment of manic-depressive illness. Biol. Psychiatry 46: 1328-1351.

Manji, H.K., McNamara, R., Chen, G., and Lenox, R.H. 1999. Signalling pathways in the brain: Cellular transduction of mood stabilisation in the treatment of manic-depressive illness. Aust. N. Z. J. Psychiatry (Suppl.) 33: 65-83.

Manji, H.K., Moore, G.J., and Chen, G. 2001. Bipolar disorder: Leads from the molecular and cellular mechanisms of action of mood stabilizers. Br. J. Psychiatry Suppl. 41: s107-s119.

Mazure, C.M. 1995. Does stress cause psychiatric illness? In Progress in psychiatry, Vol. 46 (ed. D. Spiegel), pp. 270-298. American Psychiatric Press, Washington, DC.

McGaugh, J.L. and Roozendaal, B. 2002. Role of adrenal stress hormones in forming lasting memories in the brain. Curr. Opin. Neurobiol. 12: $205-210$.

Middleton, F.A. and Strick, P.L. 2000. Basal ganglia and cerebellar loops: Motor and cognitive circuits. Brain Res. Brain Res. Rev. 31: 236-250.

Millar, J.K., Wilson-Annan, J.C., Anderson, S., Christie, S., Taylor, M.S. Semple, C.A., Devon, R.S., Clair, D.M., Muir, W.J., Blackwood, D.H., et al. 2000. Disruption of two novel genes by a translocation co-segregating with schizophrenia. Hum. Mol. Genet. 9: 1415-1423.

Millar, J.K., James, R., Brandon, N.J., and Thomson, P.A. 2004. DISC1 and DISC2: Discovering and dissecting molecular mechanisms underlying psychiatric illness. Ann. Med. 36: 367-378.

Millar, J.K., Pickard, B.S., Mackie, S., James, R., Christie, S., Buchanan, S.R., Malloy, M.P., Chubb, J.E., Huston, E., Baillie, G.S., et al. 2005. DISC1 and PDE4B are interacting genetic factors in schizophrenia that regulate cAMP signaling. Science 310: 1187-1191.

Miller, E.K. and Cohen, J.D. 2001. An integrative theory of prefrontal cortex function. Annu. Rev. Neurosci. 24: 167-202.

Miner, L.H., Jedema, H.P., Moore, F.W., Blakely, R.D., Grace, A.A., and Sesack, S.R. 2006. Chronic stress increases the plasmalemmal distribution of the norepinephrine transporter and the coexpression of tyrosine hydroxylase in norepinephrine axons in the prefrontal cortex. J. Neurosci. 26: 1571-1578.

Mirnics, K., Middleton, F.A., Stanwood, G.D., Lewis, D.A., and Levitt, P. 2001. Disease-specific changes in regulator of G-protein signaling 4 RGS4 expression in schizophrenia. Mol. Psychiatry 6: 293-301.

Mitra, R., Jadhav, S., McEwen, B.S., Vyas, A., and Chattarji, S. 2005 Stress duration modulates the spatiotemporal patterns of spine formation in the basolateral amygdala. Proc. Natl. Acad. Sci. 102: 9371-9376.

Mizoguchi, K., Yuzurihara, M., Ishige, A., Sasaki, H., Chui, D.H., and Tabira, T. 2000. Chronic stress induces impairment of spatial 
working memory because of prefrontal dopaminergic dysfunction. J. Neurosci. 20: $1568-1574$.

Muhammad, R., Wallis, J.D., and Miller, E.K. 2006. A comparison of abstract rules in the prefrontal cortex, premotor cortex, inferior temporal cortex, and striatum. J. Cogn. Neurosci. 18: 974-989.

Munafo, M.R., Bowes, L., Clark, T.G., and Flint, J. 2005. Lack of association of the COMT (Val158/108Met) gene and schizophrenia: A meta-analysis of case-control studies. Mol. Psychiatry 10: 765-770

Murphy, F.C. and Sahakian, B.J. 2001. Neuropsychology of bipolar disorder. Br. J. Psychiatry 178: 120-127.

Murphy, B.L., Arnsten, A.F., Goldman-Rakic, P.S., and Roth, R.H. 1996. Increased dopamine turnover in the prefrontal cortex impairs spatial working memory performance in rats and monkeys. Proc. Natl. Acad. Sci. 93: $1325-1329$.

Murphy, F.C., Sahakian, B.J., Rubinsztein, J.S., Michael, A., Rogers, R.D., Robbins, T.W., and Paykel, E.S. 1999. Emotional bias and inhibitory control processes in mania and depression. Psychol. Med. 29: $1307-1321$.

Nakamura, M., Salisbury, D.F., Hirayasu, Y., Bouix, S., Pohl, K.M., Yoshida, T., Koo, M.S., Shenton, M.E., and McCarley, R.W. 2007. Neocortical gray matter volume in first-episode schizophrenia and first-episode affective psychosis: A cross-sectional and longitudinal MRI study. Biol. Psychiatry 62: 773-783.

Ni, Y.G., Gold, S.J., Iredale, P.A., Terwilliger, R.Z., Duman, R.S., and Nestler, E.J. 1999. Region-specific regulation of RGS4 Regulator of G-protein-signaling protein type 4 in brain by stress and glucocorticoids: In vivo and in vitro studies. J. Neurosci. 19: $3674-3680$.

Nolan, K.A., Bilder, R.M., Lachman, H.M., and Volavka, J. 2004 Catechol-o-methyltransferase Val158Met polymorphism in schizophrenia: Differential effect of Val and Met alleles on cognitive stability and flexibility. Am. J. Psychiatry 161: 359-361.

Okamoto, K., Nagai, T., Miyawaki, A., and Hayashi, Y. 2004. Rapid and persistent modulation of actin dynamics regulates postsynaptic reorganization underlying bidirectional plasticity. Nat. Neurosci. 7: 1104-1112.

Ongur, D., An, X., and Price, J.L. 1998. Prefrontal cortical projections to the hypothalamus in macaque monkeys. J. Comp. Neurol. 401: $480-505$.

Orr, S.P. 1997. Psychophysiologic reactivity to trauma-related imagery in PTSD. Diagnostic and theoretical implications of recent findings. Ann. N. Y. Acad. Sci. 821: 114-124.

Orr, S.P., Lasko, N.B., Metzger, L.J., Berry, N.J., Ahern, C.E., and Pitman, R.K. 1997. Psychophysiologic assessment of PTSD in adult females sexually abused during childhood. Ann. N. Y. Acad. Sci. 821: 491-493.

Owen, M.J., Craddock, N., and O'Donovan, M.C. 2005. Schizophrenia: Genes at last? Trends Genet. 21: $518-525$.

Perlstein, W.M., Carter, C.S., Noll, D.C., and Cohen, J.D. 2001. Relation of prefrontal cortex dysfunction to working memory and symptoms in schizophrenia. Am. J. Psychiatry 158: 1105-1113.

Peroutka, S.J. and Synder, S.H. 1980. Relationship of neuroleptic drug effects at brain dopamine, serotonin, $\alpha$-adrenergic, and histamine receptors to clinical potency. Am. J. Psychiatry 137: 1518-1522.

Peskind, E.R., Bonner, L.T., Hoff, D.J., and Raskind, M.A. 2003. Prazosin reduces trauma-related nightmares in older men with chronic posttraumatic stress disorder. J. Geriatr. Psychiatry Neurol. 16: $165-171$

Pessoa, L. 2008. On the relationship between emotion and cognition. Nat. Rev. Neurosci. 9: 148-158.

Phillips, M.L. and Vieta, E. 2007. Identifying functional neuroimaging biomarkers of bipolar disorder: Toward DSM-V. Schizophr. Bull. 33: 893-904.

Phillips, L.J., McGorry, P.D, Garner, B., Thompson, K.N., Pantelis, C., Wood, S.J., and Berger, G. 2006. Stress, the hippocampus and the hypothalamic-pituitary-adrenal axis: Implications for the development of psychotic disorders. Aust. N. Z. J. Psychiatry 40: $725-741$

Pitman, R.K., Sanders, K.M., Zusman, R.M., Healy, A.R., Cheema, F., Lasko, N.B., Cahill, L., and Orr, S.P. 2002. Pilot study of secondary prevention of posttraumatic stress disorder with propranolol. Biol. Psychiatry 51: 189-192.

Price, J.L. 1999. Prefrontal cortical networks related to visceral function and mood. Ann. N. Y. Acad. Sci. 877: 383-396.

Radley, J.J., Sisti, H.M., Hao, J., Rocher, A.B., McCall, T., Hof, P.R., McEwen, B.S., and Morrison, J.H. 2004. Chronic behavioral stress induces apical dendritic reorganization in pyramidal neurons of the medial prefrontal cortex. Neuroscience 125: 1-6.

Radley, J.J., Rocher, A.B., Miller, M., Janssen, W.G., Liston, C., Hof, P.R., McEwen, B.S., and Morrison, J.H. 2006. Repeated stress induces dendritic spine loss in the rat medial prefrontal cortex. Cereb. Cortex 16: $313-320$.
Ragland, J.D., Yoon, J., Minzenberg, M.J., and Carter, C.S. 2007. Neuroimaging of cognitive disability in schizophrenia: Search for a pathophysiological mechanism. Int. Rev. Psychiatry 19: 417-427.

Ramos, B.P. and Arnsten, A.F.T. 2006. Adrenergic pharmacology and cognition: Focus on the prefrontal cortex. Pharmacol. Ther. 113: $523-536$

Ramos, B.P., Colgan, L., Nou, E., Ovadia, S., Wilson, S.R., and Arnsten, A.F. 2005. The $\beta-1$ adrenergic antagonist, betaxolol, improves working memory performance in rats and monkeys. Biol. Psychiatry 58: 894-900.

Ramos, B.P., Stark, D., Verduzco, L., van Dyck, C.H., and Arnsten, A.F. 2006. $\alpha 2$ A-adrenoceptor stimulation improves prefrontal cortical regulation of behavior through inhibition of cAMP signaling in aging animals. Learn. Mem. 13: 770-776.

Raskind, M.A., Peskind, E.R., Kanter, E.D., Petrie, E.C., Radant, A., Thompson, C.E., Dobie, D.J., Hoff, D., Rein, R.J., Straits-Troster, K., et al. 2003. Reduction of nightmares and other PTSD symptoms in combat veterans by prazosin: A placebo-controlled study. Am. J. Psychiatry 160: $371-373$.

Robinson, R.G., Kubos, K.L., Starr, L.B., Rao, K., and Price, T.R. 1984. Mood disorders in stroke patients. Importance of location of lesion. Brain 107: 81-93.

Rogers, J.H., Tsirka, A., Kovacs, A., Blumer, K.J., Dorn II, G.W., and Muslin, A.J. 2001. RGS4 reduces contractile dysfunction and hypertrophic gene induction in Galpha q overexpressing mice. $J$. Mol. Cell. Cardiol. 33: 209-218.

Romanski, L.M. 2004. Domain specificity in the primate prefrontal cortex. Cogn. Affect. Behav. Neurosci. 4: 421-429.

Roozendaal, B., Quirarte, G.L., and McGaugh, J.L. 2002. Glucocorticoids interact with the basolateral amygdala

$\beta$-adrenoceptor-cAMP/cAMP/PKA system in influencing memory consolidation. Eur. J. Neurosci. 15: 553-560.

Roozendaal, B., de Quervain, D.J., Schelling, G., and McGaugh, J.L. 2004a. A systemically administered $\beta$-adrenoceptor antagonist blocks corticosterone-induced impairment of contextual memory retrieval in rats. Neurobiol. Learn. Mem. 812: 150-154.

Roozendaal, B., Hahn, E.L., Nathan, S.V., de Quervain, D.J., and McGaugh, J.L. 2004b. Glucocorticoid effects on memory retrieval require concurrent noradrenergic activity in the hippocampus and basolateral amygdala. J. Neurosci. 24: 8161-8169.

Rossetti, Z.L., Portas, C., Pani, L., Carboni, S., and Gessa, G.L. 1990 Stress increases noradrenaline release in the rat frontal cortex: Prevention by diazepam. Eur. J. Pharmacol. 176: 229-231.

Rubia, K., Russell, T., Bullmore, E.T., Soni, W., Brammer, M.J., Simmons, A., Taylor, E., Andrew, C., Giampietro, V., and Sharma, T. 2001. An fMRI study of reduced left prefrontal activation in schizophrenia during normal inhibitory function. Schizophr. Res. 52: 47-55.

Rubia, K., Smith, A.B., Brammer, M.J., and Taylor, E. 2003. Right inferior prefrontal cortex mediates response inhibition while mesial prefrontal cortex is responsible for error detection. Neuroimage 20: $351-358$.

Runyan, J.D., Moore, A.N., and Dash, P.K. 2005. A role for prefrontal calcium-sensitive protein phosphatase and kinase activities in working memory. Learn. Mem. 12: 103-110.

Sandi, C. and Pinelo-Nava, M.T. 2007. Stress and memory: Behavioral effects and neurobiologic mechanisms. Neural Plast. 2007: 78970. doi: $10.1155 / 2007 / 78970$

Sara, S.J. and Herve-Minvielle, A. 1995. Inhibitory influence of frontal cortex on locus coeruleus neurons. Proc. Natl. Acad. Sci. 92: 6032-6036.

Sawaguchi, T. and Goldman-Rakic, P.S. 1991. D1 dopamine receptors in prefrontal cortex: Involvement in working memory. Science 251: $947-950$.

Sax, K.W., Strakowski, S.M., Zimmerman, M.E., DelBello, M.P., Keck Jr. P.E., and Hawkins, J.M. 1999. Frontosubcortical neuroanatomy and the continuous performance test in mania. Am. J. Psychiatry 156: $139-141$.

Schultz, W. 2007a. Behavioral dopamine signals. Trends Neurosci. 30: $203-210$.

Schultz, W. 2007b. Multiple dopamine functions at different time courses. Annu. Rev. Neurosci. 30: 259-288.

Schwendt, M., Gold, S.J., and McGinty, J.F. 2006. Acute amphetamine down-regulates RGS4 mRNA and protein expression in rat forebrain: Distinct roles of D1 and D2 dopamine receptors. J. Neurochem. 96: $1606-1615$

Seib, L.M. and Wellman, C.L. 2003. Daily injections alter spine density in rat medial prefrontal cortex. Neurosci. Lett. 337: 29-32.

Selemon, L.D. 2001. Regionally diverse cortical pathology in schizophrenia: Clues to the etiology of the disease. Schizophr. Bull. 27: $349-377$.

Selemon, L.D. and Goldman-Rakic, P.S. 1985. Longitudinal topography and interdigitation of corticostriatal projections in the rhesus 
monkey. J. Neurosci. 5: 776-794

Selemon, L.D. and Goldman-Rakic, P.S. 1988. Common cortical and subcortical targets of the dorsolateral prefrontal and posterior parietal cortex in the rhesus monkey: Evidence for a distributed neuroal network subserving spatially guided behavior. J. Neurosci. 8: $4049-4068$.

Selemon, L.D. and Goldman-Rakic, P.S. 1999. The reduced neuropil hypothesis: A circuit based model of schizophrenia. Biol. Psychiatry 45: 17-25.

Selemon, L.D, Rajkowska, G, and Goldman-Rakic, P.S. 1998. Elevated neuronal density in prefrontal area 46 in brains from schizophrenic patients: Application of a three-dimensional, stereologic counting method. J. Comp. Neurol. 392: 402-412.

Sesack, S.R. and Pickel, V.M. 1992. Prefrontal cortical efferents in the rat synapse on unlabeled neuronal targets of catecholamine terminals in the nucleus accumbens septi and on dopamine neurons in the ventral tegmental area. J. Comp. Neurol. 320: 145-160.

Sheng, M. and Hoogenraad, C.C. 2007. The postsynaptic architecture of excitatory synapses: A more quantitative view. Annu. Rev. Biochem. 76: $823-847$.

Shepherd, G.M. 1996. The dendritic spine: A multifunctional integrative unit. J. Neurophysiol. 75: 2197-2210.

Shin, L.M., Rauch, S.L., and Pitman, R.K. 2006. Amygdala, medial prefrontal cortex, and hippocampal function in PTSD. Ann. N. Y. Acad. Sci. 1071: 67-79.

Shinba, T., Briois, L., and Sara, S.J. 2000. Spontaneous and auditory-evoked activity of medial agranular cortex as a function of arousal state in the freely moving rat: Interaction with locus coeruleus activity. Brain Res. 887: 293-300.

Simons, J.S., Henson, R.N., Gilbert, S.J., and Fletcher, P.C. 2008. Separable forms of reality monitoring supported by anterior prefrontal cortex. J. Cogn. Neurosci. 20: 447-457.

Snabaitis, A.K., Muntendorf, A., Wieland, T., and Avkiran, M. 2005 Regulation of the extracellular signal-regulated kinase pathway in adult myocardium: Differential roles of Gq/11: Gi and G12/13 proteins in signalling by $\alpha 1$-adrenergic, endothelin- 1 and thrombin-sensitive protease-activated receptors. Cell. Signal. 17: 655-664.

Sobell, J.L., Richard, C., Wirching, D.A., and Heston, L.L. 2005. Failure to confirm association between RGS4 haplotypes and schizophrenia in caucasians. Am. J. Med. Genet. B Neuropsychiatr. Genet. 139B: 23-27.

Southwick, S.M., Morgan 3rd, C.A., Bremner, A.D., Grillon, C.G., Krystal, J.H., Nagy, L.M., and Charney, D.S. 1997. Noradrenergic alterations in posttraumatic stress disorder. Ann. N. Y. Acad. Sci. 821: $125-141$.

Southwick, S.M., Paige, S., Morgan 3rd, C.A., Bremner, J.D., Krystal, J.H., and Charney, D.S. 1999. Neurotransmitter alterations in PTSD: Catecholamines and serotonin. Semin. Clin. Neuropsychiatry 4: $242-248$.

Steere, J.C. and Arnsten, A.F.T. 1997. The $\alpha$-2A noradrenergic agonist, guanfacine, improves visual object discrimination reversal performance in rhesus monkeys. Behav. Neurosci. 111: 1-9.

Stefanacci, L. and Amaral, D.G. 2002. Some observations on cortical inputs to the macaque monkey amygdala: An anterograde tracing study. J. Comp. Neurol. 451: 301-323.

Strawn, J.R. and Geracioti Jr., T.D. 2007. Noradrenergic dysfunction and the psychopharmacology of posttraumatic stress disorder. Depress. Anxiety 25: 260-271.

Sullivan, E.V., Lim, K.O., Mathalon, D., Marsh, L., Beal, D.M., Harris, D., Hoff, A.L., Faustman, W.O., and Pfefferbaum, A. 1998. A profile of cortical gray matter volume deficits characteristic of schizophrenia. Cereb. Cortex 8: 117-124.

Surguladze, S.A., Chu, E.M., Evans, A., Anikumar, A.P., Patel, M.X., Timehin, C., and David, A.S. 2007. The effect of long-acting risperidone on working memory in schizophrenia: A functional magnetic resonance imaging study. J. Clin. Psychopharmacol. 27: $560-570$.

Svensson, T.H. 2003. $\alpha$-Adrenoceptor modulation hypothesis of antipsychotic atypicality. Prog. Neuropsychopharmacol. Biol. Psychiatry 27: 1145-1158.

Tait, D.S., Brown, V.J., Farovik, A., Theobald, D.E., Dalley, J.W., and Robbins, T.W. 2007. Lesions of the dorsal noradrenergic bundle impair attentional set-shifting in the rat. Eur. J. Neurosci. 25: 3719-3724.

Tan, H.Y., Callicott, J.H., and Weinberger, D.R. 2007. Dysfunctional and compensatory prefrontal cortical systems, genes and the pathogenesis of schizophrenia. Cereb. Cortex 17: 171-181.

Taylor, F.B., Lowe, K., Thompson, C., McFall, M.M., Peskind, E.R. Kanter, E.D., Allison, N., Williams, J., Martin, P., and Raskind, M.A. 2006. Daytime prazosin reduces psychological distress to trauma specific cues in civilian trauma posttraumatic stress disorder. Biol.
Psychiatry 59: 577-581.

Tovey, S.C. and Willars, G.B. 2004. Single-cell imaging of intracellular $\mathrm{Ca}^{2+}$ and phospholipase $\mathrm{C}$ activity reveals that RGS 2: 3: and 4 differentially regulate signaling via the Goq/11-linked muscarinic M3 receptor. Mol. Pharmacol. 66: 1453-1464.

Turnbridge, E.M., Bannerman, D.M., Sharp, T., and Harrison, P.J. 2004. Catechol-o-methyltransferase inhibition improves set-shifting performance and elevates stimulated dopamine release in rat prefrontal cortex. J. Neurosci. 24: 5331-5335.

Turnbridge, E.M., Harrison, P.J., and Weinberger, D.R. 2006. Catechol-o-methyltransferase: Cognition and psychosis Val158Met and beyond. Biol. Psychiatry 60: 141-151.

Turner, M.S., Simons, J.S., Gilbert, S.J., Frith, C.D., and Burgess, P.W. 2008. Distinct roles for lateral and medial rostral prefrontal cortex in source monitoring of perceived and imagined events. Neuropsychologia 46: 1442-1453.

van Haren, N.E., Bakker, S.C., and Kahn, R.S. 2008. Genes and structural brain imaging in schizophrenia. Curr. Opin. Psychiatry 21: 161-167.

Vasterling, J.J., Brailey, K., Constans, J.I., and Sutker, P.B. 1998. Attention and memory dysfunction in posttraumatic stress disorder. Neuropsychology 12: 125-133.

Ventura, J., Nuechterlein, K.H., Lukoff, D., and Hardesty, J.P. 1989. A prospective study of stressful life events and schizophrenic relapse. $J$. Abnorm. Psychol. 98: 407-411.

Vieta, E. and Phillips, M.L. 2007. Deconstructing bipolar disorder: A critical review of its diagnostic validity and a proposal for DSM-V and ICD-11. Schizophr. Bull. 33: 886-892.

Vijayraghavan, S., Wang, M., Birnbaum, S.G., Williams, G.V., and Arnsten, A.F. 2007. Inverted-U dopamine D1 receptor actions on prefrontal neurons engaged in working memory. Nat. Neurosci. 10: $376-384$.

Volk, D.W. and Lewis, D.A. 2002. Impaired prefrontal inhibition in schizophrenia: Relevance for cognitive dysfunction. Physiol. Behav. 77: 501-505.

Wallace, J.D. and Miller, E.K. 2003. From rule to response: Neuronal processes in the premotor and prefrontal cortex. J. Neurophysiol. 90: $1790-1806$.

Wang, H.Y. and Friedman, E. 1996. Enhanced protein kinase C activity and translocation in bipolar affective disorder brains. Biol. Psychiatry 40: $568-575$.

Wang, H.Y., Markowitz, P., Levinson, D., Undie, A.S., and Friedman, E. 1999. Increased membrane-associated protein kinase $C$ activity and translocation in blood platelets from bipolar affective disorder patients. J. Psychiatr. Res. 33: 171-179.

Wang, H.Y., Johnson, G.P., and Friedman, E. 2001. Lithium treatment inhibits protein kinase $\mathrm{C}$ translocation in rat brain cortex. Psychopharmacology 158: 80-86.

Wang, M., Tang, Z.X., and Li, B.M. 2004. Enhanced visuomotor associative learning following stimulation of $\alpha 2 \mathrm{~A}$-adrenoceptors in the ventral prefrontal cortex in monkeys. Brain Res. 1024: 176-182.

Wang, M., Ramos, B.P., Paspalas, C.D., Shu, Y., Simen, A., Duque, A., Vijayraghavan, S., Brennan, A., Dudley, A., Nou, E., et al. 2007. $\alpha 2 \mathrm{~A}$-adrenoceptors strengthen working memory networks by inhibiting cAMP-HCN channel signaling in prefrontal cortex. Cell 129: $397-410$

Watanabe, Y., Gould, E., and McEwen, B.S. 1992. Stress induces atrophy of apical dendrites of hippocampal CA3 pyramidal neurons. Brain Res. 588: 341-345.

Weinberger, D.R., Berman, K.F., and Zec, R.F. 1986. Physiologic dysfunction of dorsolateral prefrontal cortex in schizophrenia. I. Regional cerebral blood flow evidence. Arch. Gen. Psychiatry 43: $114-124$.

Weinberger, D.R., Berman, K.F., and Illowsky, B.P. 1988. Physiological dysfunction of dorsolateral prefrontal cortex in schizophrenia. III. A new cohort and evidence for a monoaminergic mechanism. Arch. Gen. Psychiatry 45: 609-615.

Wellcome Trust Case Control Consortium 2007. Genome-wide association study of 14,000 cases of seven common diseases and 3000 shared controls. Nature 447: 661-678.

Wellman, C.L. 2001. Dendritic reorganization in pyramidal neurons in medial prefrontal cortex after chronic corticosterone administration. I. Neurobiol. 49: 245-253.

Winterer, G. and Weinberger, D.R. 2004. Genes, dopamine and cortical signal-to-noise ratio in schizophrenia. Trends Neurosci. 27: 683-690.

Woo, T.U., Whitehead, R.E., Melchitzky, D.S., and Lewis, D.A. 1998. A subclass of prefrontal $\gamma$-aminobutyric acid axon terminals are selectively altered in schizophrenia. Proc. Natl. Acad. Sci. 95: 5341-5346.

Wood, G.E., Young, L.T., Reagan, L.P., Chen, B., and McEwen, B.S 2004. Stress-induced structural remodeling in hippocampus: Prevention by lithium treatment. Proc. Natl. Acad. Sci. 101: 3973-3978. 
Woods, D.L. and Knight, R.T. 1986. Electrophysiologic evidence of increased distractibility after dorsolateral prefrontal lesions. Neurology 36: $212-216$.

Yehuda, R., Boisoneau, D., Lowy, M.T., and Giller Jr., E.L. 1995. Dose-response changes in plasma cortisol and lymphocyte glucocorticoid receptors following dexamethasone administration in combat veterans with and without posttraumatic stress disorder. Arch. Gen. Psychiatry 52: 583-593.

Yuste, R. and Bonhoeffer, T. 2001. Morphological changes in dendritic spines associated with long-term synaptic plasticity. Annu. Rev. Neurosci. 24: 1071-1089.

Yuste, R. and Denk, W. 1995. Dendritic spines as basic functional units of neuronal integration. Nature 375: 682-684.
Yuste, R. and Majewska, A. 2001. On the function of dendritic spines. Neuroscientist 7: 387-395.

Zahrt, J., Taylor, J.R., Mathew, R.G., and Arnsten, A.F. 1997. Supranormal stimulation of D1 dopamine receptors in the rodent prefrontal cortex impairs spatial working memory performance. $J$. Neurosci. 17: 8528-8535.

Zhou, Q., Homma, K.J., and Poo, M.M. 2004. Shrinkage of dendritic spines associated with long-term depression of hippocampal synapses. Neuron 44: 749-757.

Received March 21, 2008; accepted in revised form June 4, 2008. 


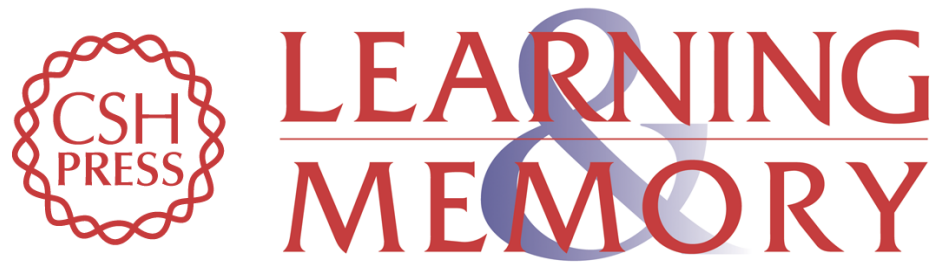

\section{Molecular mechanisms of stress-induced prefrontal cortical impairment: Implications for mental illness}

Avis B. Hains and Amy F.T. Arnsten

Learn. Mem. 2008, 15:

Access the most recent version at doi:10.1101/lm.921708

References This article cites 256 articles, 38 of which can be accessed free at: http://learnmem.cshlp.org/content/15/8/551.full.html\#ref-list-1

License

Email Alerting

Receive free email alerts when new articles cite this article - sign up in the box at the Service top right corner of the article or click here. 